\title{
Paleoecologia x Ecologia: Uma interação necessária?
}

\author{
Hanna Carolina Lins de Paiva \\ Doutoranda no Programa de Pós-graduação em Ecologia e Evolução - UERJ \\ Mestra em Ecologia e Evolução - UERJ \\ Graduação em Ciências Biológicas (Licenciatura) - UNIRIO \\ $\triangle \underline{\text { hanna.clp@gmail.com }}$ \\ Valéria Gallo \\ Professora Associada do Departamento de Zoologia, Instituto de Biologia - UERJ \\ Docente Permanente no Programa de Pós-graduação em Ecologia e Evolução (Mestrado/Doutorado) - UERJ \\ Doutora em Ciências (Geologia Sedimentar) - USP \\ Mestra em Ciências (Geologia) - UFRJ \\ Graduação em Ciências Biológicas (Licenciatura e Bacharelado) - UGF \\ $\triangle$ gallo@uerj.br
}

\section{Resumo:}

O principal objetivo da paleoecologia é reconstruir a trajetória de vida dos organismos e suas relações ao longo do tempo geológico. Embora forneça dados importantes sobre organismos e comunidades, ecólogos, em geral, não a incluem em seus estudos. Diversos métodos foram desenvolvidos e adaptados no decorrer dos séculos, a fim de promover uma melhor interação entre ecólogos e paleoecólogos. Apesar de bem conhecida, a paleoecologia ainda necessita substituir metodologias obsoletas e desenvolver novas ferramentas para sanar as questões relativas à limitação do registro fossilífero. Incontestavelmente, a maior parte dos avanços em estudos paleoecológicos está concentrada em ambientes do Quaternário. No entanto, tais resultados refletem apenas uma pequena parte da história do planeta, enquanto permanecem muitos hiatos a serem respondidos ao longo do tempo profundo. Além disso, muitas metodologias mantiveram-se por gerações na paleoecologia, mas empregá-las apenas por esta justificativa não resulta num bom argumento científico. A ecologia aplica, por exemplo, a detecção imperfeita para fornecer estimativas de riqueza de espécies, o que poderia ser uma alternativa viável para a paleoecologia. Certamente, mais estudos são necessários para sua melhor aplicação em paleoecologia, porém essa seria uma boa oportunidade de acrescer a interação entre ecólogos e paleoecólogos.

Palavras-chave: Paleoecologia do Tempo Profundo, Neoecologia, Detecção imperfeita, Diversidade, Riqueza de espécies, Uniformitarianismo.

\section{Paleoecology x Ecology: A necessary interaction?}

\begin{abstract}
:
The main goal of the paleoecology is to reconstruct the life history of organisms and their relationships over geological time. Although it furnishes important data about organisms and communities, ecologists, in general, exclude it from their studies. Several methods have been developed and adapted throughout the centuries, in order to encourage a productive interaction between ecologists and paleoecologists. Despite being a well-known science, the paleoecology still needs to replace archaic methodologies and to develop new tools to fill the typical gaps of the fossil record. Undoubtedly, most advances in paleoecological studies are concentrated in Quaternary
\end{abstract}


environments. However, such results reflect only a brief part of the Earth history, whereas many gaps in the deep-time remain to be answered. In addition, many methodologies have been maintained for generations in paleoecology without a formal justification. The ecology, for instance, applies the imperfect detection to furnish estimation of species richness, which would be a good option in paleoecology. Certainly, more studies are in need to be done, but this can be a good opportunity to increase the interaction between ecologists and paleoecologists.

Keywords: Deep-time Paleoecology, Neoecology, Imperfect Detection, Diversity, Species Richeness, Uniformitarianism.

\section{Paleoecología x Ecología: ¿una interacción necesaria?}

\section{Resumen:}

El principal objetivo de la paleoecología es reconstruir la trayectoria de vida de los organismos y sus relaciones a través del tiempo geológico. Si bien la paleoecología aporta datos importantes sobre organismos y comunidades, los ecólogos, en general, no la incluyen en sus estudios. Se han desarrollado y adaptado varios métodos a lo largo de los siglos, con el fin de promover una mejor interacción entre ecólogos y paleoecólogos. A pesar de ser bien conocida, la paleoecología todavía necesita reemplazar las metodologías antiguas y desarrollar nuevas herramientas para abordar los problemas relacionados con la limitación del registro fósil. Indudablemente, la mayoría de los avances en los estudios paleoecológicos se concentra en ambientes del Cuaternario. Sin embargo, tales resultados reflejan solo una pequeña parte de la historia del planeta, mientras que quedan muchas lagunas por resolver en el tiempo profundo. Además, muchas metodologías se han mantenido durante generaciones en paleoecología, pero emplearlas solo por esta justificación no resulta un buen argumento científico. La ecología aplica, por ejemplo, la detección imperfecta para proporcionar estimaciones de la riqueza de especies, lo que podría resultar una opción factible a la paleoecología. Ciertamente, se necesitan más estudios para su mejor aplicación en paleoecología, pero esta sería una buena oportunidad para incrementar la interacción entre ecólogos y paleoecólogos.

Palabras clave: Paleoecología profunda, Neo Ecología, Detección imperfecta, Diversidad, Riqueza de especies, Uniformismo.

\section{INTRODUÇÃo}

Ao longo da história da Terra, milhões de organismos existiram, morreram e deixaram seus nichos disponíveis a processos evolutivos, até resultarem no planeta em seu contexto atual. A paleoecologia, por sua vez, busca refazer a trajetória da vida e suas relações em escalas de tempo geológico, a fim de compreender como tais processos ocorreram (DUTRA, 2010). Para auxiliar nesse estudo, os pesquisadores envolvem pensamentos e técnicas provenientes das ciências da terra e biológicas, como tafonomia, sedimentologia, geoquímica e morfologia funcional, o que confere interdisciplinaridade à paleoecologia (FERNÁNDEZLÓPEZ, 1991; DUTRA, 2010; BIRKS, 2019).

Embora forneça dados importantes sobre organismos e comunidades, a paleoecologia não é uma ciência feita por ecólogos. Isso porque paleoecólogos precisam reconstruir ambientes e comunidades pretéritas, a partir das evidências fósseis, trabalho esse 
normalmente elaborado pela paleontologia (BIRKS, 2019). Além disso, muitas ferramentas utilizadas para a reconstrução paleoambiental vêm de outras áreas, como geologia, climatologia, antropologia e ciências ambientais, o que confere a paleoecólogos uma formação mais variada (RULL, 2010). Tal interdisciplinaridade levou a uma maior riqueza dos estudos, porém causam ainda mais falta de sinergia entre ecólogos e paleoecólogos (RULL, 2010).

Um ponto bastante debatido em paleoecologia é a limitação em decorrência do estudo com fósseis, por conta de sua natureza incompleta. Apesar de McGlone (1996) ter afirmado que dados paleoecológicos são estáticos e produzem pouco ou nenhum impacto no pensamento ecológico, outros pesquisadores (e.g. GORHAM et al., 2001; RULL, 2010), apontaram a insuficiência de resultados atuais em ecologia para resolver questões mais dinâmicas, como sucessão, estabilidade, respostas bióticas e padrões de diversidade.

Lima-Ribeiro e Diniz-Filho (2012) afirmaram que o hiato no registro fossilífero oferece algumas dificuldades nos estudos paleoecológicos, uma vez que são dependentes da existência de espécies fósseis de interesse em determinadas regiões ou período geológico. Existe, também, certa dependência entre o nível de confiança e precisão ecológica nos estudos paleoecológicos (ELDER e SMITH, 1984). Porém, com o intuito de reduzir tais limitações, novas metodologias e tecnologias foram desenvolvidas ao longo dos anos, a fim de extrair de maneira mais eficiente a informação paleoecológica do registro fossilífero (GIACOMO e FARIÑA, 2017).

No entanto, considerando a hipótese de que, apesar de ser bem conhecida, a paleoecologia ainda necessita identificar metodologias obsoletas e desenvolver novas ferramentas, assim, sanar as questões com relação à limitação no registro fóssil, a presente revisão bibliográfica tem como objetivos: (I) compreender a história e a evolução dos estudos paleoecológicos e o que isso reflete no conhecimento sobre o passado geológico; (II) identificar possíveis metodologias obsoletas e propor novas formas de abordagem em estudos paleoecológicos. 


\section{MATERIAL E MÉTODOS}

Para melhor compreender a evolução dos estudos paleoecológicos, foi utilizado o material obtido através de pesquisas em artigos disponíveis nas bases de dados Periódicos CAPES, Scielo, Science Direct, Web of Science e Wiley Online Library. Para refinar a busca, foram utilizadas palavras-chave referentes à área de paleoecologia (figura 1). Foram observadas, também, as sessões de referências de alguns artigos encontrados na busca, a fim de encontrar outros semelhantes.

Figura 1. Nuvem de palavras pesquisadas

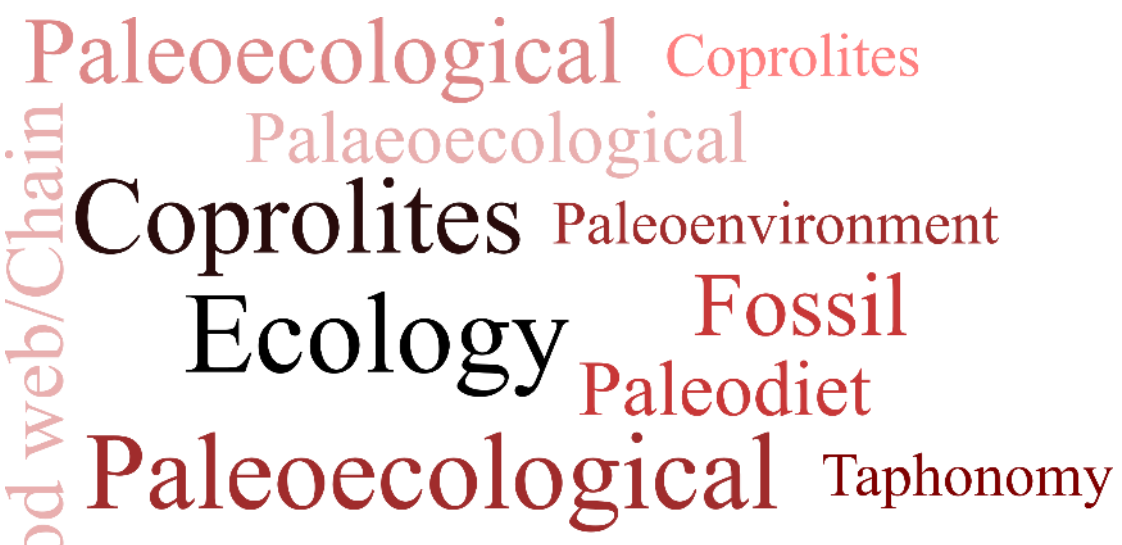

\section{Paleoecology Palaeoecology Palaeoenvironment}

Fonte: Autoria própria

Foi encontrado um total de 418 artigos. Destes, foram eliminados os de cunho arqueológico, os quais não se encaixavam no escopo de nossa pesquisa, restando, assim, os artigos de caráter paleontológico. Os artigos foram avaliados pela presença/ausência dos assuntos paleoecológicos nos estudos. Deste modo, as palavras-chave deveriam aparecer na sessão própria para isso, no título ou resumo. Além disso, foi avaliado se, de fato, os artigos apresentavam estudos paleoecológicos, através de análise dos textos.

Artigos que possuíam as palavras-chave procuradas, porém não ofereciam quaisquer inferências paleoecológicas no decorrer dos textos, nem no resumo, foram também eliminados. Por se tratarem de artigos de caráter paleontológico, foram considerados os estudos com organismos e paleoambientes que abrangiam quase todo o Fanerozoico. Assim, 
nosso limite temporal foi desde o Neoproterozoico (Pré-Cambriano) até o início do Holoceno (Cenozoico), cerca de 11.700 anos antes do presente, idade pela qual existe um consenso para um organismo ser considerado fóssil (sensu CASSAB, 2010).

Durante a identificação das metodologias, artigos que apresentavam os dados de modo mais narrativo, sem uso de cálculos estatísticos, nem geológicos, foram classificados aqui como "Descritivos".

As demais metodologias foram identificadas de acordo com o mencionado pelos próprios autores dos artigos. A seleção final resultou em 278 artigos (anexo I), com estudos referentes às eras Cenozoica, Mesozoica e Paleozoica.

\section{HISTÓRICO DA PALEOECOLOGIA}

Embora o naturalista Edward Forbes (1815-1854) seja citado como o pioneiro (WINGARD et al., 2017), os primeiros estudos paleoecológicos da História foram feitos na Grécia Antiga, os quais postulavam que os fósseis fornecem pistas sobre ambientes pretéritos (CLOUD, 1959). Além disso, o termo "paleoecologia" só foi oficialmente proposto no século XX, pelo paleobotânico Edward Wilber Berry (1875-1945), o qual afirmava que existia uma ligação entre organismos atuais, cujos hábitat, distribuição e variação seriam de grande importância para determinar a paleoecologia (WINGARD et al., 2017).

Entretanto, segundo Böger (1970) o "verdadeiro criador" do termo deveria ser F. E. Clements (1875-1945), que não apenas citou, como definiu, em 1916, a paleoecologia como "a resposta de organismos fósseis e comunidades a seus hábitats, assim como a resposta dos hábitats a seus organismos e comunidades". Roman Fedorovich Gekker (1900-1991), por sua vez, publicou o primeiro livro inteiramente dedicado à paleoecologia, Manual on Paleoecology (1933), no qual foram definidos os fundamentos e principais objetivos desta ciência (KHLODOV e OSIPOVA, 2000).

Após a Segunda Guerra Mundial, os estudos paleoecológicos tiveram um considerável aumento, devido ao surgimento da análise de isótopos estáveis de Woodring (1951). Através dela, isótopos de oxigênio poderiam ser utilizados para determinar a temperatura da água e 
resolver alguns questionamentos sobre evidências em análises paleoambientais (WINGARD et al., 2017).

Em 1957, a publicação do livro Treatise on marine ecology and paleoecology, de Joel Walker Hedgpeth (1911-2006), foi o estopim para o aumento de pesquisas sobre a paleoecologia marinha, a qual focou em grupos-chave de organismos e interpretação de aspectos físicos de ambientes passados. Com este incremento, houve também um estímulo para que a paleoecologia se tornasse uma subdisciplina na década de 1960 (SEPKOSKI, 2008). Nessa mesma época, um número considerável de paleontólogos atentou-se para o uso de dados de abundância relativa, muito úteis para inferir relações paleoecológicas (GIFFORD, 1981).

Imbrie e Kipp (1971) foram os primeiros a inserir cálculos estatísticos em estudos paleoecológicos, com o desenvolvimento do "fator analítico de função de transferência", que usa análise de fatores de regressão linear de dados em ecologia atual, aplicados em equações para avaliação de assembleias fossilíferas. As análises estatísticas em paleoecologia aumentaram nas décadas de 1980 e 1990, graças ao surgimento dos computadores e um melhor entendimento sobre as relações entre ambiente, ecologia e evolução dos processos (WINGARD et al., 2017). Já no século XXI, as pesquisas em paleoecologia, em especial no Quaternário, passaram a ser mais voltadas para a paleoecologia da conservação, na qual os estudos são utilizados para apresentar perspectivas históricas relevantes sobre a conservação da natureza e manejo de ecossistemas (BIRKS, 2019).

\section{A QUESTÃO DO UNIFORMITARIANISMO}

O uniformitarianismo é um conceito de origem geológica e de suma importância, considerado um dos princípios filosóficos essenciais da paleoecologia (GOULD, 1965). Ele postula que muitos dos processos naturais que operaram no passado podem continuar a operar no presente da mesma maneira, sem variação de grau ou intensidade, o que posteriormente foi resumido como: "o presente é a chave do passado" (BUSHMAN, 1983).

No entanto, desde que foi proposto, este princípio tem gerado debates. James Hutton (1726-1797) e Charles Lyell (1797-1875), pais da geologia moderna, são creditados pelo termo 
"uniformitarianismo". No entanto, foi Whewell (1832) que mudou o nome do até então chamado "princípio de uniformidade" (ROMANO, 2015). Lyell (1830-1833), em seu livro "Principles of Geology", dividiu a hipótese de Hutton em três princípios de uniformidade que, juntos, formariam uma contra resposta à ideia de Buckland (1837), a qual explicava o registro geológico unicamente como resultado de um "agente direto de Interferência Criativa"; em outras palavras, intervenção divina (GOULD, 1965).

Gould (1965) questionou a necessidade do uniformitarianismo em paleoecologia, o qual foi dividido em uniformitarianismo substantivo e metodológico (atualismo). Mayr (2011), por sua vez, abriu o leque de definições do uniformitarianismo, fortemente relacionadas às ideias de Lyell, Jean Baptiste Lamarck (1744-1829), Charles Robert Darwin (1809-1889) e Louis Agassiz (1807-1873).

Embora haja diversos significados com o termo uniformitarianismo, as qualidades associadas ao termo indicam apenas um único aspecto, sem sequer considerar a definição original do termo (ROMANO, 2015). Um exemplo comum de uso parcial do significado incorporado do "uniformitarianismo" é sua equivalência com "atualismo", frequentemente reconhecida como um sinônimo da frase "o presente é a chave do passado" (ROMANO, 2015).

$\mathrm{O}$ atualismo, considerado um uniformitarianismo reformulado, postula que processos atuais fornecem explicações suficientes para fenômenos geomorfológicos passados, embora os padrões de atividade desses processos possam ter variado em grau, intensidade e frequência (DONALDSON et al., 2002). No entanto, Gould (1965), Donaldson et al. (2012) e Romano (2015) apontaram que tanto uniformitarianismo quanto atualismo poderiam ser considerados termos supérfluos e, talvez, os termos "atualista" e "não atualista" seriam melhores substitutos, uma vez que fazem mais sentido em referência a processos e produtos individuais, que podem ou não ter análogos entre processos atualmente observáveis.

o termo uniformitarianismo precisa ser utilizado com cuidado, uma vez que seu significado explicaria a importância de outros termos históricos, como "atualismo" e "catastrofismo" (WALKDEN, 2019). Caso contrário, eles continuariam a ser utilizados em publicações científicas como meros slogans ou clichês (ROMANO, 2015). 


\section{EVOLUÇÃO DOS ESTUDOS PALEOECOLÓGICOS}

A Era Cenozoica (em especial o período Quaternário) representa a grande maioria ( $n=176$ artigos) dos estudos paleoecológicos, seguida das eras Mesozoica ( $n=62$ artigos) e Paleozoica ( $n=40$ artigos) (figuras 2 e 3). Esse resultado é aqui interpretado como um reflexo da divisão entre dois grandes grupos de estudo em paleoecologia, apontados por Birks (2019): Paleoecologia do Quaternário e Paleoecologia do Tempo Profundo.

Os estudos referentes ao Quaternário (Pleistoceno-Holoceno) remontam ao passado de 50.000 anos, período relativamente fácil de ser datado, por conta da presença de radiocarbono (BIRKS, 2019). Foi também durante o Quaternário que ocorreram as maiores oscilações climáticas entre estágios interglaciais temperados e glaciais frios, somados à evolução, diversificação cultural e distribuição global dos humanos, o que teria gerado os primeiros impactos ambientais da História (WINGARD et al., 2017).

Figura 2. Gráfico com o percentual de artigos para cada era geológica

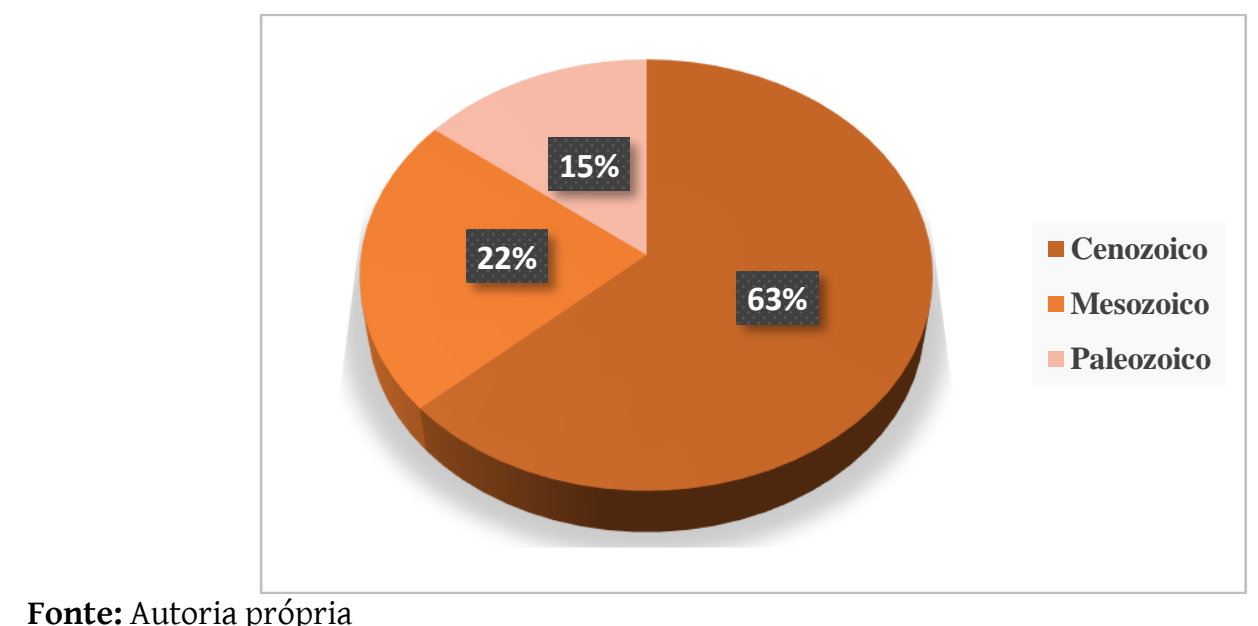


Figura 3. Publicações de artigos de paleoecologia por ano

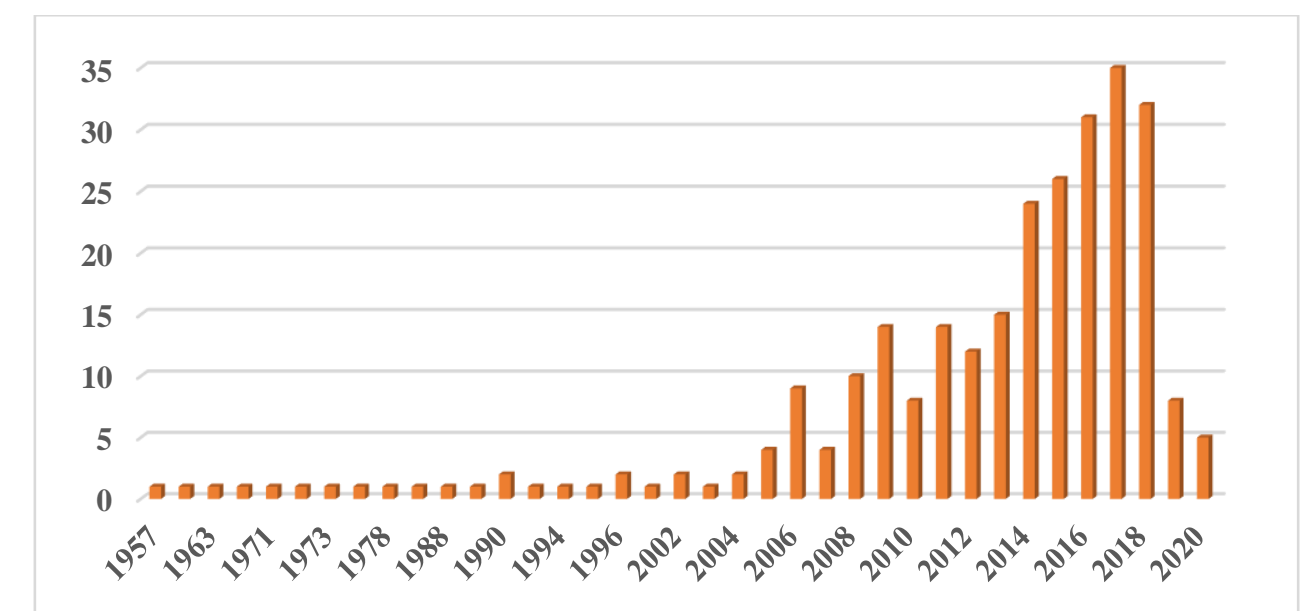

Legenda: Número de publicações referentes à paleoecologia entre os anos de 1957 e 2020 Fonte: Autoria própria

Por conta disso, além da maior atenção dada em estudos de paleoecologia referentes a humanos (os quais se referem à Arqueologia, que não foram considerados no escopo dessa revisão), muitos estudos em Paleoecologia do Quaternário vêm ganhando destaque, por trazerem contribuições sobre a "saúde" dos ecossistemas e a história de detecção de impactos devido às mudanças climáticas nos sistemas biológicos (BIRKS, 2019). A importância da Paleoecologia da Conservação, como é conhecida a nova linha de pesquisa, reside no fato de promover novas perspectivas históricas, relevantes para a conservação da natureza e manejo de ecossistemas (BIRKS, 2019).

Lindbladh et al. (2013) apontaram que estudos paleoecológicos apresentam aspecto fundamental para uma conservação efetiva, o que levaria, também, a uma integração entre ecólogos, paleoecólogos e biólogos da conservação. No entanto, tais contribuições, embora importantes para melhor entendimento de dinâmicas ecológicas e conservação, são restritas a intervalos de tempo curtos, de décadas ou mesmo milênios (PELLATT et al., 2015; BIRKS, 2019). Desse modo, ainda que seja promissora, a Paleoecologia da Conservação (ou mesmo a Paleoecologia do Quaternário como um todo) traz luz apenas a um passado relativamente recente, cuja proximidade com o presente permite uma melhor resolução sobre reconstruções paleoambientais e as dinâmicas entre os organismos, enquanto um verdadeiro hiato permanece na Paleoecologia do Tempo Profundo. Some-se a isso a falsa perspectiva de "passado distante", como se todo o tempo profundo fosse comprimido numa faixa, o que Lima-Ribeiro e Diniz-Filho (2013) denominaram achatamento paleontológico logarítmico. 
Com relação aos grupos mais estudados em Paleoecologia (figura 4), foi observado que cinco grupos mais se destacaram ao longo dos anos. Entre eles, os mamíferos estão presentes em 31,2\% (n=87 artigos) dos artigos, normalmente relacionados à reconstrução de paleodieta e/ou paleoambiental. o segundo grupo mais frequente em estudos paleoecológicos é o das plantas e palinomorfos (pólens e esporos), aqui reunido no termo "paleobotânica", representando 15,1\% ( $\mathrm{n}=42$ artigos), registrado tanto no Paleozoico, quanto Mesozoico e Cenozoico.

Assim como o "grupo" paleobotânica, os demais grupos aqui citados são registrados em estudos referentes às três eras geológicas. $O$ terceiro lugar é ocupado pelos microfósseis, com 13,3\% ( $\mathrm{n}=37$ artigos), comumente associados à reconstrução paleoambiental e a taxas de produtividade. Por sua vez, artrópodes ocupam o quarto lugar (8,27\%, n= 23 artigos), com estudos referentes a reconstrução paleoambiental, padrão de diversidade, respostas a perturbações paleoambientais e sucessão ecológica.

Já o quinto grupo mais estudado é representado pelos peixes com 5,75\% dos estudos ( $\mathrm{n}=16$ artigos), relacionados a reconstrução paleoambiental e compreensão sobre relações tróficas. Finney et al. (2010) afirmaram que, conforme os registros paleoecológicos são mais antigos no tempo geológico, eles tendem a ser menos influenciados por atividades antrópicas e conferem uma melhor compreensão sobre flutuações nas populações de peixes e dinâmicas do ecossistema.

Ainda, para alguns autores (e.g. SCHÄFER, 1972; WILSON, 1989; MELO, 2011), peixes seriam os melhores indicadores paleoambientais, devido a sua sensibilidade a processos de decomposição e posteriores processos tafonômicos. Assim, a tafonomia de peixes pode fornecer pistas sobre limnologia, composição de comunidades, história de vida, mortalidade em massa e ambientes deposicionais, que podem auxiliar, também, na reconstrução paleoambiental (ELDER e SMITH, 1988). No entanto, a tafonomia não foi observada em tais estudos, os quais recorreram a outras abordagens, tais como análises isotópicas e abundância relativa para melhor compreender as paleocomunidades de peixes. 
Figura 4.Principais grupos de organismos estudados em paleoecologia

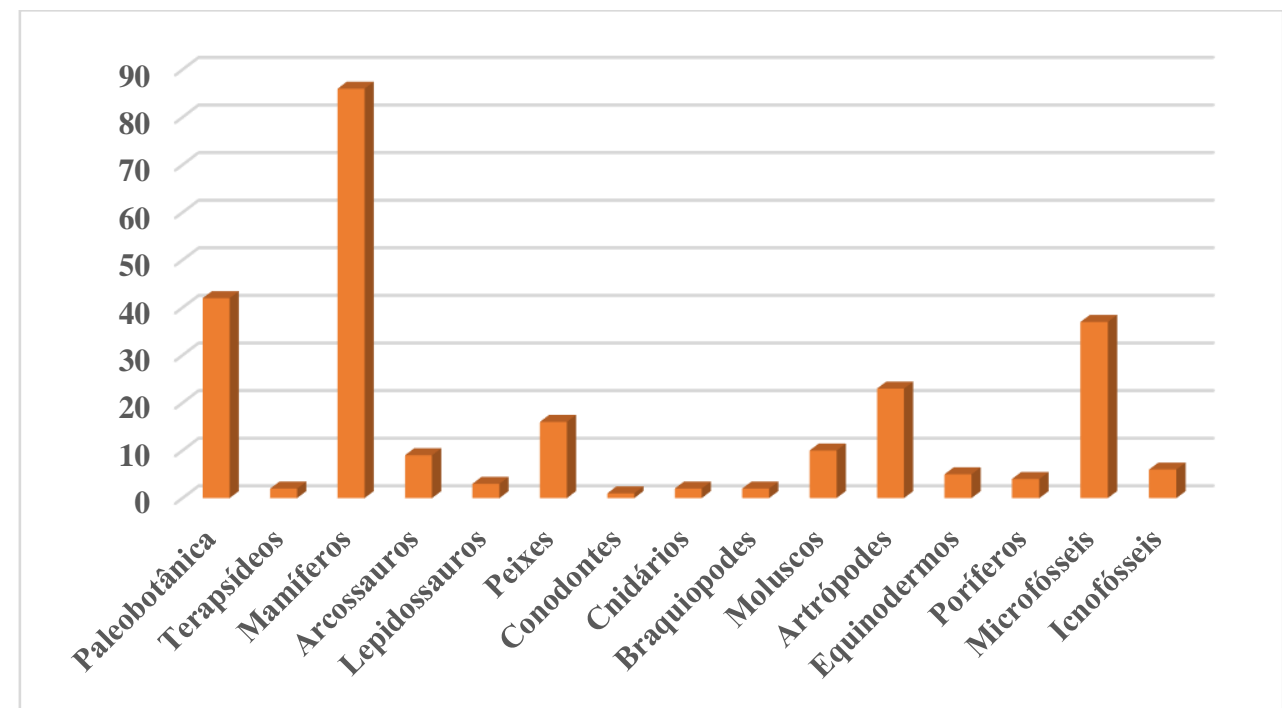

Legenda: Resultados observados em artigos de 1957 até 2020. Fonte: Autoria própria

As principais abordagens em paleoecologia (figura 5) são a reconstrução paleoambiental (43,8\%, n=120 artigos) (e.g. MONDAL et al., 2014; WYNN et al., 2016), seguida de reconstrução de paleodieta $(15,3 \%, n=42)$ (e.g. BAJDEK et al., 2017; VAJDA et al., 2016) e compreensão sobre relações tróficas (5,8\%, n=16 artigos) (e.g. DANTAS et al., 2017; FRANÇA et al., 2015). A reconstrução paleoambiental pode ser baseada em algumas espécies indicadoras ou na assembleia fossilífera como um todo (BIRKS, 2019). Existe certo equívoco com relação ao tema, uma vez que a paleoecologia não é simplesmente uma reconstrução paleoambiental, porém pode fornecer dados necessários para tal (RULL, 2010). Dessa forma, a paleoecologia seria parte de uma metodologia, não o único objetivo do estudo paleoambiental (RULL, 2010). Esse equívoco poderia ser explicado pelo poder homogeneizador do prefixo paleo- em pesquisas de zoologia, botânica, geografia, ecologia, entre outros, conforme apontado por Rull (2010). Por conta disso, é comum observar em trabalhos "paleoclimatologia” e “paleoecologia" como sinônimos, quando, na verdade, não são (RULL, 2010). Apesar de o clima ser considerado parte do ecossistema e de reconstruções paleoclimáticas serem necessárias para uma compreensão ecológica adequada, considerar que paleoclimatologistas e paleoecólogos são equivalentes seria aceitar que meteorologistas são ecólogos (RULL, 2010). 
Figura 5. Principais abordagens em paleoecologia

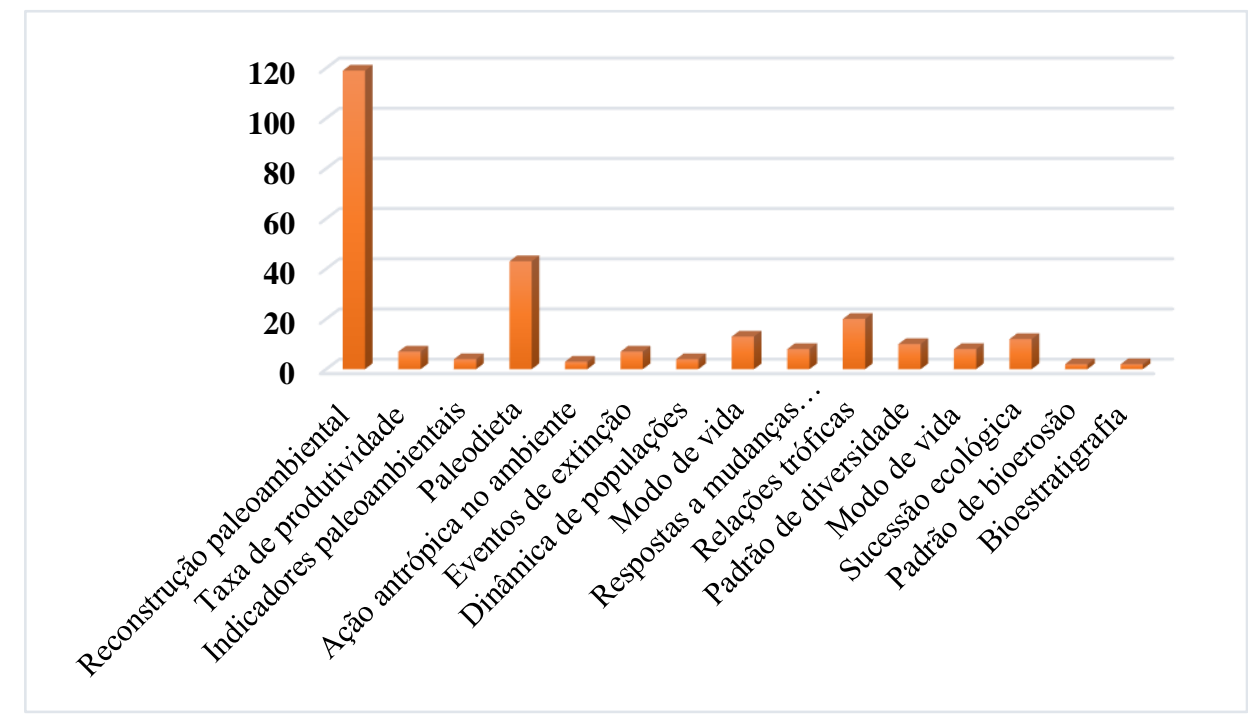

Legenda: Resultados observados em artigos de 1957 até 2020.

Fonte: Autoria própria

Os estudos de paleodieta podem contribuir com informações sobre interações ecológicas, através de análise de vestígios fósseis (fezes ou conteúdo estomacal) (VELÁZQUEZ et al., 2015), ou indiretamente, a partir dos dentes, com base em comparações com espécies atuais, e pelos padrões de uso (FORTELIUS e SOLOUNIAS, 2000). No entanto, grande parte dos resultados $(21,8 \%)$ mostrou que dados de isótopos estáveis são os mais utilizados para reconstrução de paleodieta (figura 6) e permitem identificar padrões na paleodieta e/ou preferências de hábitat em, por exemplo, representantes da megafauna (BRAVO-CUEVAS et al., 2017). Dentre os artigos analisados (e.g. BELMAKER, 2018; STACKLYN et al., 2017), foi observado que este tipo de análise normalmente baseia-se em carbono e oxigênio, e, algumas vezes, em enxofre e nitrogênio. Os isótopos de carbono, nitrogênio e enxofre estão mais relacionados a vias fotossintéticas, normalmente conservados ao longo da teia alimentar (KOCH, 2007; MARSHALL et al., 2007; PEREIRA, 2007). Por sua vez, os isótopos estáveis de oxigênio são derivados de ingestão de água do ambiente e estão presentes nos tecidos dos mamíferos (KOCH, 2007). Apesar de alguns autores (e.g. KOCH, 2007; MARSHALL et al., 2007; BRAVO-CUEVAS et al., 2017; BIRKS, 2019) terem relacionado a análise de isótopos estáveis apenas à paleodieta de mamíferos do Quaternário, como se fosse a única finalidade da técnica, essa metodologia pode ser aplicada a táxons mais antigos, bem como a estudos paleoclimatológicos e paleoecológicos do Paleozoico e Mesozoico, para a identificação de eventos de extinção em massa, dinâmicas populacionais, sucessão ecológica e no auxílio à 
reconstrução paleoambiental (e.g. HORI et al., 2011; BAJDEK et al., 2017; NIKITENKO et al., 2018). Cabe ressaltar que a proposta original dos estudos utilizando isótopos estáveis, na década de 1950 (veja WOODRING, 1951), era exatamente auxiliar geoquímicos e paleo-oceanógrafos a compreender os ciclos globais dos elementos, como uma forma de inferir os climas pretéritos, sistemas de expansão hidrotérmicos e a origem das formações rochosas (LAJTHA e MICHENER, 1994; PEREIRA, 2007). Embora tenha sido desenvolvida para paleoecologia, tal metodologia acabou por chegar ao conhecimento dos ecólogos a partir da década de 1980, sendo utilizada até os dias atuais, com a finalidade de interpretar a estequiometria ecológica (PETERSON e FRY, 1987).

Um fato curioso verificado no levantamento bibliográfico aqui realizado foi a alta frequência de artigos puramente descritivos, sem aplicação de uma metodologia ecológica/paleoecológica explícita e robusta (figura 6) (e.g. BUSH et al., 2004; SMITH e DESANTIS, 2018). Apesar de Gifford (1981) ter afirmado que o foco nos artigos de paleoecologia deixou de ser puramente descritivo na década de 1960, ele ainda é comum entre publicações depois dos anos 2000. Tal fato poderia ser explicado pela não utilização de metodologias atualmente adotadas em ecologia, as quais poderiam enriquecer mais ainda estudos paleoecológicos. Isso seria devido à própria limitação de estudos paleoecológicos diante dos hiatos no registro fossilífero, conforme apontado anteriormente por Lima Ribeiro e Diniz-Filho (2012), o que impediria a aplicação de certos métodos, restando apenas estudos descritivos como melhor opção para os pesquisadores.

Além disso, dada à interdisciplinaridade da paleoecologia, muitos pesquisadores possuem uma formação que não exige treinamento em ecologia, especialmente em ecologia quantitativa. Desse modo, haveria uma falta de familiaridade com os métodos e, consequentemente, a sua não-utilização em estudos paleoecológicos. Gifford (1981) apontou, ainda, uma falta de sinergia entre ecólogos e paleoecólogos, o que, provavelmente, gerou certa estase nos estudos durante tanto tempo. Consequências dessa estase foram apontadas em Gould $(1970,1976)$, que ressaltou a ausência de fundamentação filosófica na pesquisa paleoecológica. Simpson (1970) afirmou que essa carência gerou tratados inteiros de paleoecologia, sem mencionar a existência do uniformitarianismo ou o papel de observações contemporâneas ao assumir a significância dos padrões no registro fossilífero. Essa falta de atenção seria também responsável por sérios problemas na paleoecologia, os quais forjam a ilusão de progresso (LAWRENCE, 1971; GIFFORD, 1981). 
Figura 6. Principais metodologias utilizadas em paleoecologia

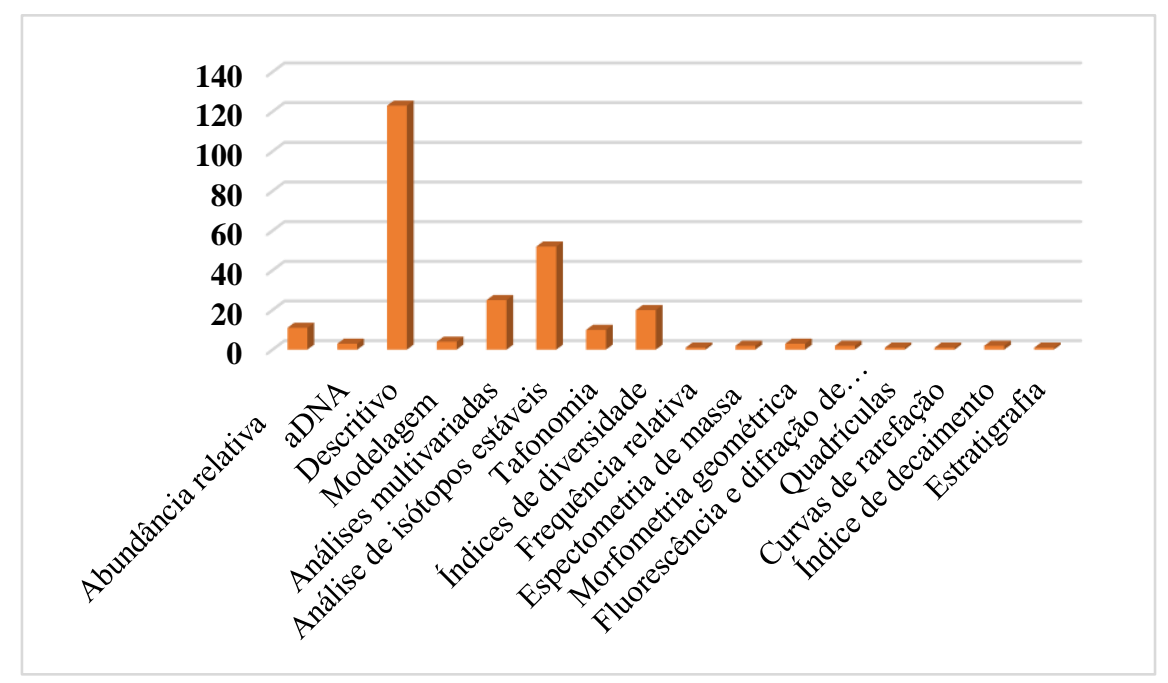

Legenda: Resultados observados em artigos de 1957 até 2020.

Fonte: Autoria própria

O terceiro objetivo mais buscado em paleoecologia é a compreensão sobre relações tróficas (e.g. GREEN et al., 2017; NG e TENG, 2014) (figura 6), com enfoque probabilístico e numérico (ROOPNARINE, 2009, 2010). Isso porque o registro fossilífero pode ser de grande importância na compreensão do desenvolvimento das teias alimentares ao longo do tempo, respondendo até às maiores perturbações ambientais, uma vez que a análise das paleoteias permite inferir as interações tróficas entre as espécies e as comunidades em que estão inseridas (WILF, 2008). No entanto, Wilf (2008) também afirmou que, conforme se avança mais profundamente no tempo, mais difícil se torna a inferência inequívoca sobre a diversidade e composição de mais de um nível da teia alimentar. Tal discrepância foi refletida nos resultados aqui obtidos, pois a maioria dos estudos envolvendo relações tróficas englobam ambientes do Cenozoico (55\%) e Mesozoico (30\%), enquanto poucos estudos foram registrados para o Paleozoico (15\%).

Dentre esses estudos sobre relações tróficas, destacam-se, principalmente, aqueles sobre herbivoria. De acordo com Barrett e Willis (2001), a herbivoria é um dos níveis mais fundamentais nessas relações e alvo de intensos estudos sobre as associações mutualísticas entre animais herbívoros e as plantas. A abundância das plantas, somada à palatabilidade e às distribuições espacial e temporal afetam diretamente as populações de herbívoros, modificando taxas de densidade, migração, sobrevivência e sucesso reprodutivo (CRAWLEY, 1983). 
Embora os resultados aqui apresentados mostrem artigos com esse tema desde o final da década de 1950 (SHOTWELL, 1958), muitos estudos recentes incluem as interações insetoplanta (e.g. LABANDEIRA et al., 2002; LABANDEIRA e CURRANO, 2013), dinossauros-flores (e.g. BARRETT e WILLIS, 2001; BUTLER et al., 2008) e padrão de alimentação preferencial de mamíferos (e.g. FRANÇA et al., 2015; DANTAS et al., 2017). Parte desses estudos inclui análise de isótopos estáveis, tafonomia, ou estão inclusos no grupo dos artigos descritivos.

Estudos ainda mais amplos e complexos foram desenvolvidos por ROOPNARINE (2009), analisando as teias alimentares de duas paleocomunidades e suas relações interespecíficas. Uma destas comunidades é referente ao Permiano superior continental da Bacia do Karoo, na África do Sul, e a outra é proveniente do Mioceno superior marinho costeiro da República Dominicana. Para o estudo de ambas as paleoteias, ROOPNARINE (2009) criou e aplicou o modelo CEG (Cascading Extinction on Graphs). Este modelo analisa como e em que extensão as interações na paleocomunidade afetam a capacidade das espécies resistirem ao que denominou "extinção secundária", ou seja, a extinção de certas espécies dentro da comunidade em decorrência da extinção de outras, num efeito cascata.

\section{O PROBLEMA DOS ÍNDICES DE DIVERSIDADE}

Com relação às metodologias, além das análises de isótopos estáveis e artigos puramente descritivos, anteriormente comentados, foi observado que uma metodologia recorrente é o uso de análises multivariadas, em especial os índices de diversidade (e.g. GILBERT et al., 2018; KRAPOVICKAS et al., 2009; MANDIC et al., 2002). Estes são utilizados geralmente para calcular taxas de abundância e diversidade, identificar eventos de sucessão ecológica dos organismos e/ou de eventos de extinção. Os índices de diversidade são ferramentas úteis ao estimar a qualidade biológica e ecológica de um ecossistema, através da estrutura de uma comunidade, combinando dois atributos distintos, como riqueza de espécies e equitabilidade (BANDEIRA et al., 2013). No entanto, Melo (2008) apontou que o uso de dois atributos distintos seria, na verdade, uma "sensação" ingênua, pois estes seriam também independentes do esforço amostral, os quais seriam expressos através de fórmula estatística. 
Porém, a presença de fórmulas estatísticas complexas, pode levar à ilusão de um padrão (MELO, 2008).

Os índices de diversidade mais utilizados em paleoecologia são os de Shannon (1948) e de Simpson (1949). Ambos são considerados índices não paramétricos, que relacionam abundância relativa das espécies através de expressões matemáticas simples (MELO, 2008). Embora bastante conhecido, Bandeira et al. (2013) alertaram que o índice de Shannon nunca pode ser calculado de fato, apenas estimado e corresponderia à medida da entropia física, além de ser insensível às espécies raras, as quais tem um papel importante no ecossistema. Por sua vez, Melo (2008) argumentou que os dados obtidos do índice de Shannon, assim como outros índices de diversidade, são restritos a situações comparativas, o que nem sempre é possível em estudos com fósseis. Já o índice de Simpson tem como objetivo original medir a "concentração de classificação" em termos de populações constantes, uma noção inversa de diversidade (BANDEIRA et al., 2013). Krebs (1972), por sua vez, tentou uma abordagem diferente e propôs uma nova definição para o índice de Simpson, indicando a probabilidade de duas espécies escolhidas ao acaso e determinadas independentemente pertencer a espécies diferentes, a qual tem sido a mais utilizada, inclusive por paleoecólogos.

No entanto, os índices de Shannon e Simpson são atualmente considerados obsoletos em estudos ecológicos (MELO, 2008). Um dos maiores problemas é a falta de critérios na escolha de qual índice de diversidade utilizar. Isso porque todos os índices de diversidade geram infinitas combinações de riqueza de espécies com equitabilidade e a escolha de um determinado índice pode influenciar o padrão obtido, enquanto outro índice pode resultar num padrão distinto (MELO, 2008). Tal dúvida também é recorrente na paleoecologia, uma vez que ainda não está claro qual o melhor índice de diversidade para estudos com registro fossilífero, levando-se em consideração que o mesmo tem, por definição, natureza incompleta e pode gerar certa confusão no momento de inferir abundância, diversidade ou mesmo riqueza de espécies.

Melo (2008) apontou quatro alternativas ao uso de índices de diversidade em ecologia, sendo duas delas aplicáveis também à paleoecologia. A primeira delas e a mais comum dentre todas as métricas de diversidade (WILSEY et al., 2005) é o cálculo da riqueza de espécies somente. A riqueza é o componente mais importante na diversidade das espécies, então apenas ela seria necessária para compreender a diversidade de uma comunidade (MA, 2005). 
No entanto, apesar da facilidade de interpretação, identificar um padrão de diversidade nas comunidades apenas com base na contagem de espécies pode mascarar a estrutura quantitativa da comunidade, e mesmo, as espécies raras (MA, 2005; WILSEY et al., 2005).

Outra alternativa seria o uso dos perfis de diversidade (PEET, 1974). O melhor índice a ser usado dentro do perfil de diversidade é aquele que vai além do uso de riqueza de espécies unicamente (Mendes et al., 2008). Uma forma de utilizar os perfis de diversidade poderia ser através de softwares estatísticos, como o R (MENDES et al., 2008), especificamente o pacote “vegan" (OKSANEN et al., 2019).

Por outro lado, em paleoecologia, muitas espécies são consideradas raras ou abundantes, apenas se considerando os fósseis encontrados na localidade, quando na verdade elas apenas estavam nas condições possíveis de fossilização (=processos tafonômicos), porém podem não refletir o número real de indivíduos da população que existiu no paleoambiente. Ainda, para cada grupo taxonômico estudado, deve ser considerado o período geológico e a faixa da paleolatitude em que ele ocorreu, os quais interferem nos fatores biológicos e geológicos de maneiras distintas (SIMÕES et al., 2010).

Assim, os processos de fossilização são frutos de uma equação de muitas variáveis, o que interfere na quantidade e qualidade de fósseis encontrados no registro fossilífero (BEHRENSMEYER et al., 2000; SIMÕES et al., 2010). Além disso, no registro sedimentar, existem vários hiatos de diversas ordens de grandeza, os quais resultam de uma série de processos que culminam num registro muito incompleto (HOLZ et al., 2010). Dessa forma, é relativamente difícil conferir raridade, abundância ou mesmo diversidade a uma espécie.

A raridade das espécies é objeto de fascínio de ecólogos e biólogos evolutivos (VIOLLE et al., 2017). Entretanto, o conceito de raridade/abundância ainda é um tanto obscuro no âmbito da paleoecologia, principalmente por conta da natureza incompleta e do modo de detecção de tais variações nas comunidades pretéritas. Vários estudos demonstraram que o modo de detecção das espécies varia ao longo do tempo, entre espécies e ambientes (KELLNER e SWIHART, 2014). Ignorar tais variações pode gerar consequências sérias, pois pode enviesar os resultados e gerar impactos negativos na qualidade dos dados, levando a falsas ausências de espécies raras ou difíceis de identificar (KÉRY e SCHMIDT, 2008). 
Porém, tentando sanar os hiatos enfrentados em paleoecologia, referentes à abundância, à diversidade e, mesmo, à presença de espécies raras em paleoecologia, uma alternativa seria a utilização da detecção imperfeita. Embora ainda necessite de ajustes para sua melhor aplicação em paleoecologia, a detecção parece ser uma ferramenta promissora para aplicação em fósseis, em especial os registrados em assembleias que remontam cenários de morte não seletiva, pois a quantidade de indivíduos permite estimar a composição e estrutura da paleocomunidade. Tal ferramenta leva em consideração que algumas espécies são praticamente impossíveis de serem totalmente computadas através de um censo. Exemplos desse tipo de análise incluem estudos em peixes atuais de água doce, os quais estão entre os grupos mais ameaçados e mais complicados de serem amostrados, dado o tipo de hábitat em que vivem e aspectos de sua biologia (RICCIARDI e RASMUSSEN, 1999).

Benoit et al. (2018) realizaram um estudo com peixes atuais, através de modelos de ocupação, os quais demonstraram que a detecção imperfeita pode, de fato, influenciar nas estimativas de riqueza das espécies e a estrutura da comunidade. Os modelos de ocupação, combinados com métodos de ordenação multivariada, mostraram de forma robusta quais espécies e locais podem ser mais susceptíveis a impactos da detecção imperfeita. Além disso, é de suma importância que os valores limitantes numa comunidade sejam levados em consideração, pois podem influenciar drasticamente as estimativas de riqueza e outras métricas, o que também influencia o desenvolvimento e base de uma teoria ecológica (BENOIT et al., 2018).

Britton et al. (2011) testaram a detecção imperfeita em populações de Pseudorasbora parva, uma espécie asiática de peixe introduzida em lagos da Europa, através de aquicultura. Considerada uma espécie invasora, $P$. parva tem baixa densidade populacional, normalmente não detectada em censos, o que gera dados falso-negativos e prejudicam programas de manejo de espécies invasoras. Através do estudo, Briton et al. (2011) quantificaram a detecção imperfeita e relacionaram com a densidade populacional conhecida, por métodos de amostragem e esforço de pesquisa que não a utilizavam. Desse modo, os autores observaram que quantificar o uso de detecção imperfeita pode melhorar substancialmente o modelo das estratégias de busca, o que, por sua vez, produz menos chances de erros nos resultados. 


\section{CONSIDERAÇÕES FINAIS}

Há uma visão positiva com relação aos avanços em pesquisas paleoecológicas e maior comunicação entre pesquisadores nas últimas décadas. No entanto, tal comunicação só existe quando considerada a Paleoecologia do Quaternário, enquanto ambientes mais antigos (como no Mesozoico e Paleozoico), têm recebido relativamente pouca atenção no decorrer desses 62 anos. Como consequência, há, ainda, muitos hiatos a serem respondidos ao longo do tempo profundo. Tais hiatos são devidos a uma dissociação psicológica entre passado e futuro, a qual continua sendo transmitida através das ciências biológicas (RULL, 2010). Por conta disso, a paleoecologia segue sendo pouco utilizada pelos ecólogos ao explicar padrões e processos ecológicos atuais.

Desde a década de 1950, muitas metodologias mantiveram-se, sem muita alteração, reconhecidas como a única ferramenta viável para uso em fósseis. Isso porque "os paleontólogos relutariam em se envolver em prolongadas discussões teóricas quando havia trabalho prático de natureza aparentemente simples a ser feito" (GIFFORD, 1981, p. 482). Ainda, a formação variada dos paleontólogos, a qual pode não ter a necessidade de treinamento em ecologia e seus métodos, poderia estar ligada a essa estase, a qual gerou repetições de métodos ecológicos considerados obsoletos por décadas. No entanto, utilizar uma determinada metodologia simplesmente por ser utilizada por gerações não resulta num bom argumento científico (MELO, 2008).

Apesar de ser uma alternativa para solucionar as questões dos hiatos no registro fossilífero ao quantificar riqueza de espécies, bem como outras métricas, a detecção imperfeita ainda necessita de mais estudos para sua melhor aplicação em paleoecologia. De qualquer forma, essa seria uma oportunidade de tentar diminuir a falta de sinergia entre ecólogos e paleoecólogos, como uma forma de fazer duas vertentes de uma ciência caminharem juntas, além de abrir a porta para novas ideias e possibilitar uma nova compreensão sobre a relação dos organismos com ambientes pretéritos. 


\section{AGRADECIMENTOS}

Aos Drs. Hermínio Ismael de Araújo Jr, Mauro Cavalcanti, Paulo Machado Brito e Richard A. Fariña, pelas inestimáveis contribuições concedidas, as quais resultaram neste artigo. HCLP agradece à Coordenação de Aperfeiçoamento de Pessoal de Nível Superior (CAPES) pela bolsa concedida, à Universidade do Estado do Rio de Janeiro e ao Programa de Pós-graduação em Ecologia e Evolução, os quais permitiram as pesquisas desta revisão bibliográfica. VG agradece ao Conselho Nacional de Desenvolvimento Científico e Tecnológico (CNPq) pela bolsa de produtividade em pesquisa e à Fundação Carlos Chagas Filho de Amparo à Pesquisa do Estado do Rio de Janeiro (FAPERJ/UERJ) pela bolsa do Programa de Incentivo à Produção Científica, Técnica e Artística (PROCIÊNCIA). O presente trabalho foi realizado com apoio da Coordenação de Aperfeiçoamento de Pessoal de Nível Superior - Brasil (CAPES) - Código de Financiamento 001.

\section{REFERÊNCIAS}

BAJDEK, P.; OWOCKI, K.; SENNIKOV, A. G.; GOLUBEV, V. K.; NIEDŹWIEDZKI, G. Residues from the Upper Permian carnivore coprolites from Vyazniki in Russia - key questions in reconstruction of feeding habits. Palaeogeography, Palaeoclimatology, Palaeoecology, v. 482, p. 70-82, 2017.

BANDEIRA, B.; JAMET, J. L.; JAMET, D.; GINOUX, J. M. Mathematical convergences of biodiversity indices. Ecological Indicators, v. 29, p. 522-528, 2013. DOI: https://doi.org/10.1016/j.ecolind.2013.01.028

BARRETT, P. M.; WILLIS, K. J. Did dinosaurs invent flowers? Dinosaur-angiosperm coevolution revisited. Biological Reviews, v. 76, p. 411-447, 2001.

BEHRENSMEYER, A. K.; KIDWELL, S. M.; GASTALDO, R. A. Taphonomy and paleobiology. Paleobiology, v. 26, p. 103-147, 2000.

BELMAKER, M. Insights from carnivore community composition on the paleoecology of early Pleistocene Eurasian sites: Implications for the dispersal of hominins out of Africa. Quaternary International, v. 464, p. 3-17, 2018.

BENOIT, D.; JACKSON D. A.; RIDGWAY, M. S. Assessing the impacts of imperfect detection on estimates of diversity and community structure through multispecies occupancy modeling. Ecology and Evolution, v. 8, p. 4676-4684, 2018. DOI: https://doi.org/10.1002/ece3.4023

BIRKS, H. J. B. Paleoecology. p. 494-504. In: B. Fath (ed.). Encyclopedia of Ecology. Elsevier, Towson, Maryland. 2019.

BÖGER, H. Bildung und gebrauch von begriffen in der paläoökologie. Lethaia, v. 3, p. 243-269, 1970. 
BRAVO-CUEVAS, V. M.; RIVALS, F.; PRIEGO-VARGAS, J. Paleoecology ( $\delta 13 \mathrm{C}$ and $\boldsymbol{\delta} 180$ stable isotopes analysis) of a mammalian assemblage from the late Pleistocene of Hidalgo, central Mexico and implications for a better understanding of environmental conditions intemperate North America (18 ${ }^{\circ}-$ $36^{\circ} \mathrm{N}$ Lat.). Palaeogeography, Palaeoclimatology, Palaeoecology, v. 485, p. 632-643, 2017. DOI: https://doi.org/10.1016/j.palaeo.2017.07.018

BRITTON, J. R.; PEGG, J.; GOZLAN, R. E. Quantifying imperfect detection in an invasive pest fish and the implications for conservation management. Biological Conservation, 144: 2177-2181, 2011. DOI: https://doi.org/10.1016/j.biocon.2011.05.008

BUCKLAND, W. Geology and mineralogy considered with reference to natural theology. Lea and Blanchard, Philadelphia, Carev, 1837.

BUSH, M. B.; DE OLIVEIRA, P. E.; COLINVAUX, P. A.; MILLER, M. C.; MORENO, J. E. Amazonian paleoecological histories: one hill, three watersheds. Palaeogeography, Palaeoclimatology, Palaeoecology, v. 214, p. 359-393, 2004.

BUSHMAN, J. R. Hutton's Uniformitarianism. Brigham Young University Studies, v. 23, n. 1, p. 41-48, 1983.

BUTLER, R. J.; BARRETT, P. M.; PAUL KENRICK, P.; PENN, M. G. Testing co-evolutionary hypotheses over geological timescales: interactions between Mesozoic non-avian dinosaurs and cycads. Biological Reviews, v. 84, p. 73-89, 2008. DOI:10.1111/j.1469-185X.2008.00065.X

CASSAB, R. C. T. Objetivos e princípios. p. 3-11. In: Souza, I.S.C. (ed.). Paleontologia-Conceitos e Métodos 1, Editora Interciência, 2010.

CLEMENTS, F. E. Plant Succession: An Analysis of the Development of Vegetation. Washington, DC, Carnegie Institute of Washington Publication, 1916.

CLOUD, P. E. Paleoecology: retrospect and prospect. Journal of Paleontology, v. 33, p. 926-962, 1959.

CRAWLEY, M. J. Herbivory: The Dynamics of Animal-Plant Interactions. Oxford: Blackwell Scientific Publications, 1983.

DANTAS, M. A. T.; CHERKINSKY, A.; BOCHERENS, H.; DREFAHL, M.; BERNARDES, C.; FRANÇA, L. M. Isotopic paleoecology of the Pleistocen e megamam mals from the Brazilian Intertropic al Regio n: Feeding ecology ( d13C), niche breadth and overlap. Quaternary Science Reviews, v. 170, p. 152-163, 2017.

DONALDSON, J. A; ERIKSSON, P. G.; ALTERMANN, W. Actualistic versus non-actualistic conditions in the Precambrian sedimentary record: reapprasial of an enduring discussion. Special Publications of the International Association of Sedimentologists, 33: 3-13, 2002. DOI: https://doi.org/10.1002/9781444304312.ch1

DUTRA, T. L. Paleoecologia. p. 339-349. In: Souza, I.S.C. (ed.). Paleontologia - Conceitos e métodos 1, Editora Interciência, 2010.

ELDER, R. L.; SMITH, G. R. Fish taphonomy and paleoecology. Geobios, Memóire Spécial, v. 8, p. 287-291, 1984.

ELDER, R. L.; SMITH, G. R. Fish taphonomy and environmental inference in paleolimnology. Palaeogeography, Palaeoclimatology, Palaeoecology, v. 62, p. 577-592, 1988.

FERNÁNDEZ-LÓPEZ, S. Taphonomic concepts for a theoretical biochronology. Revista Española Paleontología, v. 6, n. 1, p. 37-49, 1991.

FINNEY, B. P.; ALHEIT, J.; EMEIS, K. C.; FIELD, D. B.; GUTIÉRREZ, D.; STRUCK, U. Paleoecological studies on variability in marine fi sh populations: A long-term perspective on the impacts of climatic change on marine ecosystems. Journal of Marine Systems, v. 79, p. 316-326, 2010. DOI: 10.1016/j.jmarsys.2008.12.010 
FORTELIUS, M.; SOLOUNIAS, N. Functional characterization of ungulate molars using the abrasionattrition wear gradient: A new method for reconstructing paleodiets. American Museum Novitates, v. 3301, n. 36, p. 1-36, 2000. Disponível em: http://hdl.handle.net/2246/2957. Acesso em 23/07/2019.

FRANÇA, L. M.; ASEVEDO, L.; DANTAS, M. A. T.; BOCCHIGLIERI, A.; AVILLA, L. S.; LOPES, R. P.; SILVA, J. L. L. Review of feeding ecology data of Late Pleistocene mammalian herbivores from South America and discussions on niche differentiation. Earth-Science Reviews, v. 140, p. 158-165, 2015. DOI: http://dx.doi.org/10.1016/j.earscirev.2014.10.006

GEKKER, R. F. Polozheniya i Instruktsiya dlya Ussledovaniy po Paleoekologii [Principles and Instruction for Paleoecological Investigations]. Northwestern Geological Prospecting Trust, 1933.

GIÁCOMO, M. D.; FARIÑA, R. A. Allometric models in paleoecology: Trophic relationships among Pleistocene mammals. Palaeogeography, Palaeoclimatology, Palaeoecology, v. 471, p. 15-30, 2017. DOI: https://doi.org/10.1016/j.palaeo.2017.01.040

GIFFORD, D. P. Taphonomy and paleoecology: A critical review of archeology's sister disciplines. p. 365-438. In: Schiffer, M. (ed.). Advances in archeological method and theory 4, Academic Press, 1981.

GILBERT, M. M.; BAMFORTH, E. L.; BUATOIS, L. A.; RENAUT, R. W. Paleoecology and sedimentology of a vertebrate microfossil assemblage from the easternmost Dinosaur Park Formation (Late Cretaceous, Upper Campanian,) Saskatchewan, Canada: Reconstructing diversity in a coastal ecosystem. Palaeogeography, Palaeoclimatology, Palaeoecology, v. 495, p. 227-244, 2018 . DOI: https://doi.org/10.1016/j.palaeo.2018.01.016

GORHAM, E.; BRUSH, G. S.; GRAUMLICH, L. J.; ROSENZWEIG, M. L.; JOHNSON, A. H. The value of paleoecology as an aid to monitoring ecosystems and landscapes, chiefly with reference to North America. Environmental Reviews, v. 9, p. 99-126, 2001. DOI: 10.1139/er-9-2-99

GOULD, S. J. Is uniformitarianism necessary? American Journal of Science, v. 263, p. 223-228, 1965.

GOULD, S. J. Dollo on Dollo's law: Irreversibility and the status of evolutionary laws. Journal of the History of Biology, v. 3, p. 189-212, 1970.

GOULD, S. J. Paleontology plus Ecology as Paleobiology. p. 295-317. In: May, R. M. (ed.). Theoretical Ecology: Principles and Applications, Sinauer Associates, 1976.

GREEN, J. L.; DESANTIS, L. R. G.; SMITH, G. J. Regional variation in the browsing diet of Pleistocene Mammut americanum (Mammalia, Proboscidea) as recorded by dental microwear textures. Palaeogeography, Palaeoclimatology, Palaeoecology, v. 487, p. 59-70, 2017. DOI: http://dx.doi.org/10.1016/j.palaeo.2017.08.019

HEDGPETH, J. W. Treatise on Marine Ecology and Paleoecology 1: Ecology. Baltimore, Geological Society of America, 1957.

HOLZ, M.; BERTONI-MACHADO, C.; SIMÕES, M. G. A estratigrafia de sequências e o registro fóssil. p. 111-137. In: Souza, I.S.C. (ed.). Paleontologia-Conceitos e métodos 1, Editora Interciência, 2010.

HORI, R. S.; YAMAKITA, S.; IKEHARA, M.; KODAMA, K.; AITA, Y.; SAKAI, T.; TAKEMURA, A.; KAMAT, Y.; SUZUKI, N.; TAKAHASHI, S.; SPÖRLI, K. B.; GRANT-MACKIE, J. A. Early Triassic (Induan) Radiolaria and carbon-isotope ratios of a deep-sea sequence from Waiheke Island, North Island, New Zealand. Palaeoworld, v. 20, p. 166178, 2011.

IMBRIE, J.; KIPP, N. G. A new micropaleontological method for quantitative paleoclimatology: application to a Late Pleistocene Caribbean core. p. 71-181. In: K. K. Turekian (ed.). The Late Cenozoic Glacial Ages, Yale University Press, 1971.

KELLNER, K. F.; SWIHART, R. K. 2014. Accounting for Imperfect Detection in Ecology: A Quantitative Review. PlosOne, 2014. Disponível em: e111436. doi:10.1371/journal.pone.0111436. Acesso em 19/08/2019. 
KÉRY, M.; SCHMIDT, B. R. Imperfect detection and its consequences for monitoring for conservation. Community Ecology, v. 9, p. 207-216, 2008. DOI: 10.1556/ComEc.9.2008.2.10

KHOLODOV, V. N.; OSIPOVA, A. I. The 100th Birthday of Roman Fedorovich Gekker. Lithology and Mineral Resources, v. 35, n. 6, p. 499-503, 2000. DOI: 10.1023/A:1026699213327

KOCH, P. L. Isotopic study of the biology of modern and fossil vertebrates. p. 99-154. In: R. Michener and K. Lajtha (eds.). Stable Isotopes in Ecology and Environmental Science. 2a edição. Blackwell Publishing, 2007.

KRAPOVICKAS, V.; CICCIOLI, P. L.; MÁNGANO, M. G.; MARSICANO, C. A.; LIMARINO, C. O. Paleobiology and paleoecology of an arid-semiarid Miocene South American ichnofauna in anastomosed fluvial deposits. Palaeogeography, Palaeoclimatology, Palaeoecology, v. 284, p. 129-152, 2009. DOI: 10.1016/j.palaeo.2009.09.015

KREBS, C. J. Ecology, the experimental analysis of distribution and abundance. Harper \& Row, 1972.

LABANDEIRA, C. C.; CURRANO, E. D. The Fossil Record of Plant-Insect Dynamics. Annual Review of Earth and Planetary Sciences, v. 41, n. 13, p. 1-13, 2013. DOI: 10.1146/annurev-earth-050212-124139

LABANDEIRA, C. C.; JOHNSON, K. R.; WILF, P. Impact of the terminal Cretaceous event on plant-insect associations. Procceedings of the National Academy Sciences, v. 99, n. 4, p. 2061-2066, 2002. DOI: www.pnas.org cgi doi 10.1073 pnas.042492999

LAJTHA, K.; MICHENER, R. H. Stable isotopes in ecology and environmental science. Oxford: Blackwell Scientific Publications, 1994.

LAWRENCE, D. R. The nature and structure of paleoecology. Journal of Paleontology, v. 45, p. 593-607, 1971.

LIMA-RIBEIRO, M. S.; DINIZ-FILHO, J. A. F. Modelando a distribuição biogeográfica das espécies no passado: uma abordagem promissora em paleoecologia. Revista Brasileira de Paleontologia, v. 15, n. 3, p. 371-385, 2012. DOI: $10.4072 / \mathrm{rbp} .2012 .3 .12$

LIMA-RIBEIRO, M. S.; DINIZ-FILHO, J. A. F. Modelos Ecológicos e a Extinção da Megafauna: clima e homem na América do Sul. São Carlos, Editora Cubo, 155 p., 2013.

LINDBLADH, M.; FRAVER, S.; EDVARDSSON, J.; FELTON, A. Past forest composition, structures and processes - How paleoecology can contribute to forest conservation. Biological Conservation, v. 168, p. 116-127, 2013. DOI: http://dx.doi.org/10.1016/j.biocon.2013.09.021

MA, M. Species richness vs evenness: independent relationship and different responses to edaphic factors. Oikos, v. 111, n. 1, p. 192-198, 2005. DOI: 10.1111/j.0030-1299.2005.13049.x

MANDIC, O.; HARZHAUSER, M.; SPEZZAFERRI, S.; ZUSCHIN, M. The paleoenvironment of an early Middle Miocene Paratethys sequence in NE Austria with special emphasis on paleoecology of mollusks and foraminifera. Geobios, v. 35, n. 24, p. 193-206, 2002.

MARSHALL, J. D.; BROOKS, J. R.; LAJTHA, K. Sources of variation in the stable isotopic composition of plants. p. 22-60. In: R.Michener and K. Lajtha (eds.). Stable Isotopes in Ecology and Environmental Science. 2a edição. Blackwell Publishing, 2007.

MAYR, E. Storia del Pensiero Biologico. Diversità, Evoluzione, Eredità. Bollati Boringhieri. Torino, Gruppo editoriale Mauri Spagnol, 2011.

MCGLONE, M. S. When history matters: scale, time, climate and tree diversity. Global Ecology and Biogeography, v. 5, p. 309-14, 1996.

MELO, A. S. O que ganhamos 'confundindo' riqueza de espécies e equabilidade em um índice de diversidade? Biota Neotropica, v. 8, n. 3, p. 021-027, 2008. DOI: 10.1590/S1676-06032008000300001 
MELO, R. S. P. F. Análise tafonômica da ictiofauna da Formação Morro do Chaves, Cretáceo Inferior da Bacia de Sergipe-Alagoas, Nordeste do Brasil. 2011. 181f. Tese (Doutorado), Programa de Pós-Graduação em Biociências, Instituto Roberto Alcantara Gomes/Universidade do Estado do Rio de Janeiro, 2011.

MENDES, R. S.; EVANGELISTA, L. R.; THOMAZ, S. M.; AGOSTINHO, A. A.; GOMES, L. C. A unifid index to measure ecological diversity and species rarity. Ecography, v. 31, n. 4, p. 450-456, 2008. DOI: https://doi.org/10.1111/j.0906-7590.2008.05469.x

MONDAL, S.; HARRIES, P. J.; PAUL, S.; HERBERT, G. S. Paleoecological signifi cance of coupling metrics of successful and unsuccessful shell-breaking predation: Examples using Neogene bivalve prey. Palaeogeography, Palaeoclimatology, Palaeoecology, v. 399, p. 89-97, 2014.

NG, T.-W.; TENG, L. S. Quantitative paleoecological analyses and implications of fossil assemblages of the Late Neogene Kangkou Limestone, Coastal Range, eastern Taiwan. Palaeoworld, v. 23, p. 69-89, 2014. DOI: http://dx.doi.org/10.1016/j.palwor.2013.10.003

NIKITENKO, B. L.; PESTCHEVITSKAYA, E. B.; KHAFAEVA, S. N. High-resolution stratigraphy and palaeoenvironments of theVolgian-Valanginian in the Olenek key section (Anabar-Lena region, Arctic East Siberia, Russia). Revue de micropaléontologie, v. 61, p. 271-312, 2018. DOI: https://doi.org/10.1016/j.revmic.2018.07.001

OKSANEN, J.; KINDT, R.; LEGENDRE, P.; O'HARA, B.; HENRY, M.; STEVENS, H. Vegan: Community Ecology Package. $\quad \mathbf{R}$ package, version 1. p. 8-8, 2019. Disponível em: https://cran.rproject.org/web/packages/vegan/index.html. Acesso em 27/08/2020.

PEET, R. K. The measurement of species diversity. Annual Review of Ecollogy, Evolution and Systematics, v. 5, p. 285-307, 1974.

PELLATT, M. G.; MCCOY, M. M.; MATHEWES, R. W. Paleoecology and fire history of Garry oak ecosystems in Canada: implications for conservation and environmental management. Biodiversity and Conservation, v. 24, n. 7, p. 1621-1639, 2015. DOI: https://doi.org/10.1007/s10531-015-0880-1

PEREIRA, A. L. Isótopos estáveis em estudos ecológicos: métodos, aplicações e perspectivas. Revista Biociências, v. 13, n. 1-2, p. 16-27, 2007.

PETERSON, B. J.; FRY, B. Stable isotopes in ecosystem studies. Annual Review of Ecology and Systematics, v. 18, p. 293-320, 1987. DOI: https://doi.org/10.1146/annurev.es.18.110187.001453

RICCIARDI, A.; RASMUSSEN, J. B. Extinction rates of North American freshwater fauna. Conservation Biology, v. 13, n. 5, p. 1220-1222, 1999. DOI: https://doi.org/10.1046/j.1523-1739.1999.98380.x

ROMANO, M. Reviewing the term uniformitarianism in modern Earth sciences. Earth-Science Reviews, v. 148, p. 65-76, 2015. DOI: 10.1016/j.earscirev.2015.05.010

ROOPNARINE, P. D. Ecological modeling of paleocommunity food webs. p. 195-220. In: G. P. Dietl and K. W. Flessa (eds.). Conservation Paleobiology: Using the Past to Manage for the Future. Paleontological Society Short Course, 2009.

ROOPNARINE, P. D. Networks, extinction and paleocommunity food webs. p. 143-161. In: J. Alroy and G. Hunt (eds.). Quantitative Methods in Paleobiology. Paleontological Society Short Course, 2010.

RULL, V. Ecology and Palaeoecology: Two Approaches, One Objective. The open ecology journal, v. 3, p. 1-5, 2010. DOI: $10.2174 / 1874213001003020001$

SCHÄFER, W. Ecology and paleoecology of marine environments. University of Chicago Press, Chicago. 1972. 
SEPKOSKI, D. Evolutionary paleontology and the fossil record: a historical introduction. p. 41-53. In: P. H. Kelley and R. K. Bambach (eds.). From Evolution to Geobiology: Research Questions Driving Paleontology at the Start of a New Century. The Paleontological Society Papers, Yale University Printing. 2008.

SHANNON, C. E. A mathematical theory of communication. The Bell System Technical Journal, v. 22, n. 3, p. 379423, 1948.

SHOTWELL, A Inter-Community Relationships in Hemphillian (Mid-Pliocene) Mammals. Ecology, v. 39, n. 2, p. 271-282, 1958.

SIMÕES, M. G.; RODRIGUES, S. C.; BERTONI-MACHADO, C.; HOLZ, M. Tafonomia: Processos e ambientes de fissilização. p. 19-51. In: Souza, I.S.C. (ed.). Paleontologia-Conceitos e Métodos 1, Editora Interciência, 2010.

SIMPSON, E. H. Measurement of diversity. Nature, v. 163, p. 688, 1949.

SIMPSON, G. G. Uniformitarianism. An inquiry into principle, theory, and method in geohistory and biohistory. p. 4396. In: İ. K. HECHT; W. C. STEERE (eds.). Essays in evolution and genetics in honor of Theodosius Dobzhansky, Appleton, New York. 1970.

SMITH, G. J.; DESANTIS, L. R. G. Dietary ecology of Pleistocene mammoths and mastodons as inferred from dental microwear textures. Palaeogeography, Palaeoclimatology, Palaeoecology, v. 492, p. 10-25, 2018.

STACKLYN, S.; WANG, Y.; JIN, C. et al. Carbon and oxygen isotopic evidence for diets, environments and niche differentiation of early Pleistocene pandas and associated mammals in South China. Palaeogeography, Palaeoclimatology, Palaeoecology, v. 468, p. 351-36, 2017. DOI: http://dx.doi.org/10.1016/j.palaeo.2016.12.015

VELÁZQUEZ, N. J.; BURRY, L. S.; FUGASSA, M. H. Palynological analysis of extinct herbivore dung from Patagonia, Argentina. Quaternary International, v. 377, p. 140-147, 2015. DOI: https://doi.org/10.1016/j.quaint.2015.05.012

VIOLLE, C.; THUILLER, W.; MOUQUET, N.; et al. Functional Rarity: The Ecology of Outliers. Trends in Ecology and Evolution, v. 32, n. 5, p. 356-367, 2017. DOI: https://doi.org/10.1016/j.tree.2017.02.002

WALKDEN, W. The many faces of uniformitarianism in linguistics. Glossa, v. 4, n. 1, p. 1-17, 2019. DOI: http://doi.org/10.5334/gjgl.888

WHEWELL, W. Principles of geology By Charles Lyell, Esq. F.R.S., Professor of Geology in King's College, London. Vol II. London. Quarterly Reviews, v. 47, p. 103-132, 1832.

WILF, P. Insect-damaged fossil leaves record food web response to ancient climate change and extinction. New Phytologist, v. 178, p. 486-502, 2008. DOI: 10.1111/j.1469-8137.2008.02395.X

WILSEY, B. J.; CHALCRAFT, D. R.; BOWLES, C. M.; WILLIG, M. R. Relationships among indices suggest that richness is an incomplete surrogate for grassland biodiversity. Ecology, v. 86, n. 5, p. 1178-1184, 2005. DOI: https://doi.org/10.1890/04-0394

WILSON, M. V. H. Taphonomic processes: Information loss and information gain. Geoscience Canada, v. 15, p. 131 $-148,1989$.

WINGARD, G. L.; BERNHARDT, C. E.; WACHNICKA, A. H. The role of paleoecology in restoration and resource management-the past as a guide to future decision-making: Review and example from the Greater Everglades Ecosystem, U.S.A. Frontiers in Ecology and Evolution, v. 5, n. 11, p. 1-24, 2017. DOI: https://doi.org/10.3389/fevo.2017.00011

WOODRING, W. P. Basic assumption underlying paleoecology (abstract). Science, v. 113, p. 482-483, 1951.

WYNN, J. G.; REED, K. E.; SPONHEIMER, M.; KIMBEL, W. H.; ALEMSEGED, Z.; BEDASO, Z. K.; CAMPISANO, C. J. Dietary flexibility of Australopithecus afarensis in the face of paleoecological change during the middle Pliocene: Faunal evidence from Hadar, Ethiopia. Journal of Human Evolution, v. 99, p. 93-106, 2016. 


\section{ANEXO 1 - SELEÇÃO FINAL DE ARTIGOS UTILIZADOS NO TRABALHO}

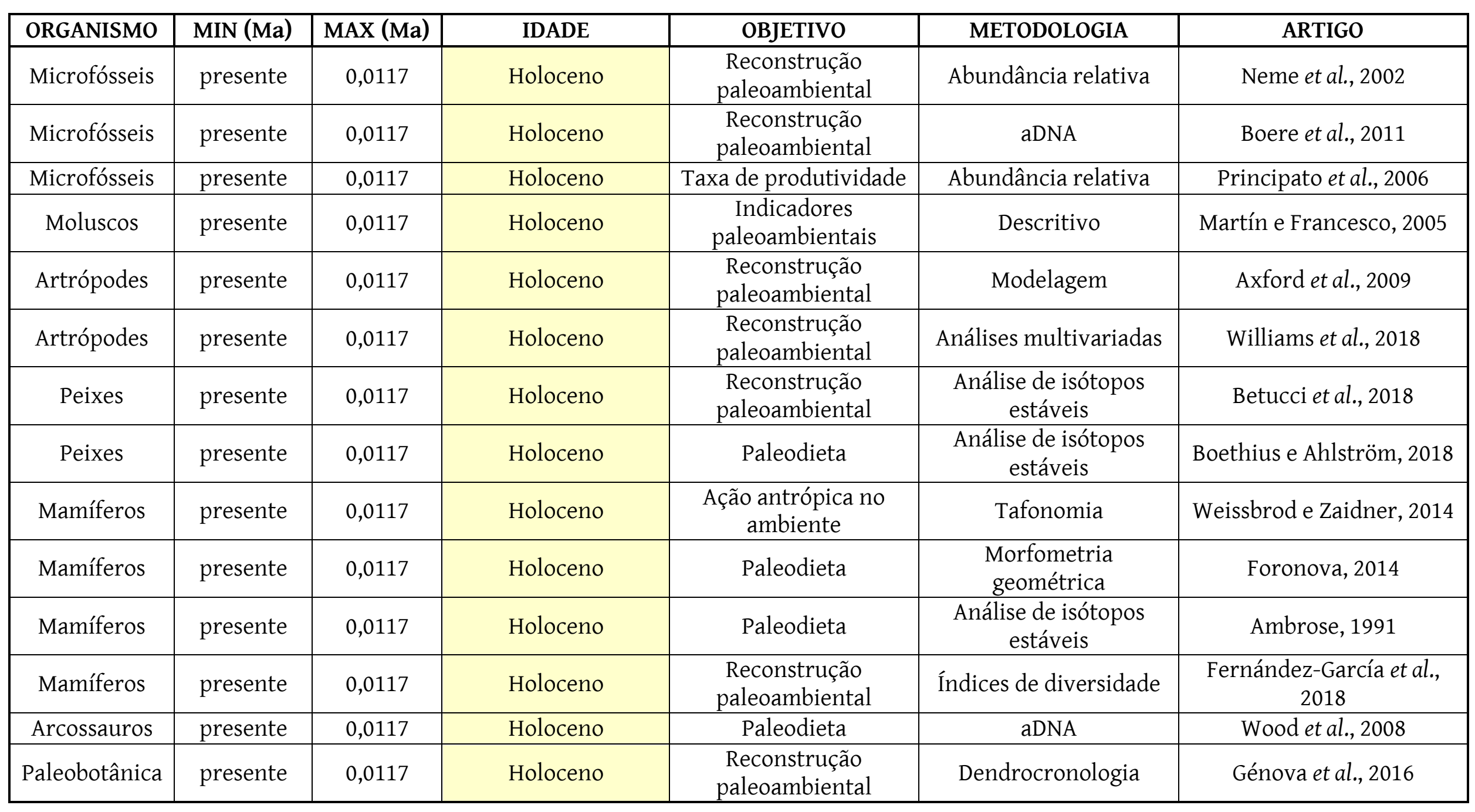




\begin{tabular}{|c|c|c|c|c|c|c|}
\hline Paleobotânica & presente & 0,0117 & Holoceno & $\begin{array}{l}\text { Reconstrução } \\
\text { paleoambiental }\end{array}$ & Descritivo & $\begin{array}{c}\text { Hermanowski, Costa e } \\
\text { Bheling, } 2012\end{array}$ \\
\hline Paleoincêndios & presente & 0,0117 & Holoceno & $\begin{array}{c}\text { Reconstrução } \\
\text { paleoambiental }\end{array}$ & Descritivo & Rull et al., 2015 \\
\hline Artrópodes & presente & 2,58 & $\begin{array}{l}\text { Pleistoceno- } \\
\text { Holoceno } \\
\text { (Quaternário) }\end{array}$ & $\begin{array}{l}\text { Reconstrução } \\
\text { paleoambiental }\end{array}$ & $\begin{array}{c}\text { Análise de isótopos } \\
\text { estáveis }\end{array}$ & Chávez-Lara et al., 2015 \\
\hline Mamíferos & presente & 2,58 & $\begin{array}{l}\text { Pleistoceno- } \\
\text { Holoceno } \\
\text { (Quaternário) }\end{array}$ & Eventos de extinção & Índice de decaimento & Ávilla et al., 2013 \\
\hline Mamíferos & presente & 2,58 & $\begin{array}{c}\text { Pleistoceno- } \\
\text { Holoceno } \\
\text { (Quaternário) }\end{array}$ & Paleodieta & Análise geoquímica & $\begin{array}{l}\text { Velázquez, Burry e } \\
\text { Fugassa, } 2015\end{array}$ \\
\hline Moluscos & presente & 2,58 & $\begin{array}{c}\text { Pleistoceno- } \\
\text { Holoceno } \\
\text { (Quaternário) }\end{array}$ & $\begin{array}{l}\text { Dinâmica de } \\
\text { populações }\end{array}$ & Índices de diversidade & $\begin{array}{l}\text { Charó, Gordillo e Fucks, } \\
2013\end{array}$ \\
\hline Moluscos & presente & 2,58 & $\begin{array}{l}\text { Pleistoceno- } \\
\text { Holoceno } \\
\text { (Quaternário) }\end{array}$ & $\begin{array}{l}\text { Reconstrução } \\
\text { paleoambiental }\end{array}$ & Frequência relativa & Sümegi et al., 2015 \\
\hline Moluscos & presente & 2,58 & $\begin{array}{c}\text { Pleistoceno- } \\
\text { Holoceno } \\
\text { (Quaternário) }\end{array}$ & Padrão de diversidade & Análises multivariadas & Francesco e Hassan, 2009 \\
\hline
\end{tabular}




\begin{tabular}{|c|c|c|c|c|c|c|}
\hline Moluscos & presente & 2,58 & $\begin{array}{c}\text { Pleistoceno- } \\
\text { Holoceno } \\
\text { (Quaternário) }\end{array}$ & Modo de vida & Tafonomia & Cárdenas e Gordillo, 2009 \\
\hline Artrópodes & presente & 2,58 & $\begin{array}{c}\text { Pleistoceno- } \\
\text { Holoceno } \\
\text { (Quaternário) }\end{array}$ & $\begin{array}{l}\text { Reconstrução } \\
\text { paleoambiental }\end{array}$ & Análises multivariadas & $\begin{array}{l}\text { Verschuren e Eggermont, } \\
2006\end{array}$ \\
\hline Artrópodes & presente & 2,58 & $\begin{array}{c}\text { Pleistoceno- } \\
\text { Holoceno } \\
\text { (Quaternário) }\end{array}$ & $\begin{array}{l}\text { Reconstrução } \\
\text { paleoambiental }\end{array}$ & Descritivo & Massaferro, 2009 \\
\hline Mamíferos & presente & 2,58 & $\begin{array}{c}\text { Pleistoceno- } \\
\text { Holoceno } \\
\text { (Quaternário) }\end{array}$ & Paleodieta & $\begin{array}{c}\text { Análise de isótopos } \\
\text { estáveis }\end{array}$ & Rotti et al., 2018 \\
\hline Paleobotânica & presente & 2,58 & $\begin{array}{c}\text { Pleistoceno- } \\
\text { Holoceno } \\
\text { (Quaternário) }\end{array}$ & $\begin{array}{l}\text { Reconstrução } \\
\text { paleoambiental }\end{array}$ & Descritivo & Freitas et al., 2015 \\
\hline Paleobotânica & presente & 2,58 & $\begin{array}{c}\text { Pleistoceno- } \\
\text { Holoceno } \\
\text { (Quaternário) }\end{array}$ & $\begin{array}{l}\text { Reconstrução } \\
\text { paleoambiental }\end{array}$ & Raio X dispersivo & Sun et al., 2019 \\
\hline Paleobotânica & presente & 2,58 & $\begin{array}{c}\text { Pleistoceno- } \\
\text { Holoceno } \\
\text { (Quaternário) }\end{array}$ & $\begin{array}{l}\text { Reconstrução } \\
\text { paleoambiental }\end{array}$ & Análises multivariadas & Toledo et al., 2009 \\
\hline Microfósseis & 0,0117 & 2,58 & Pleistoceno & $\begin{array}{c}\text { Indicadores } \\
\text { paleoambientais }\end{array}$ & Abundância relativa & Shimada et al., 2008 \\
\hline
\end{tabular}




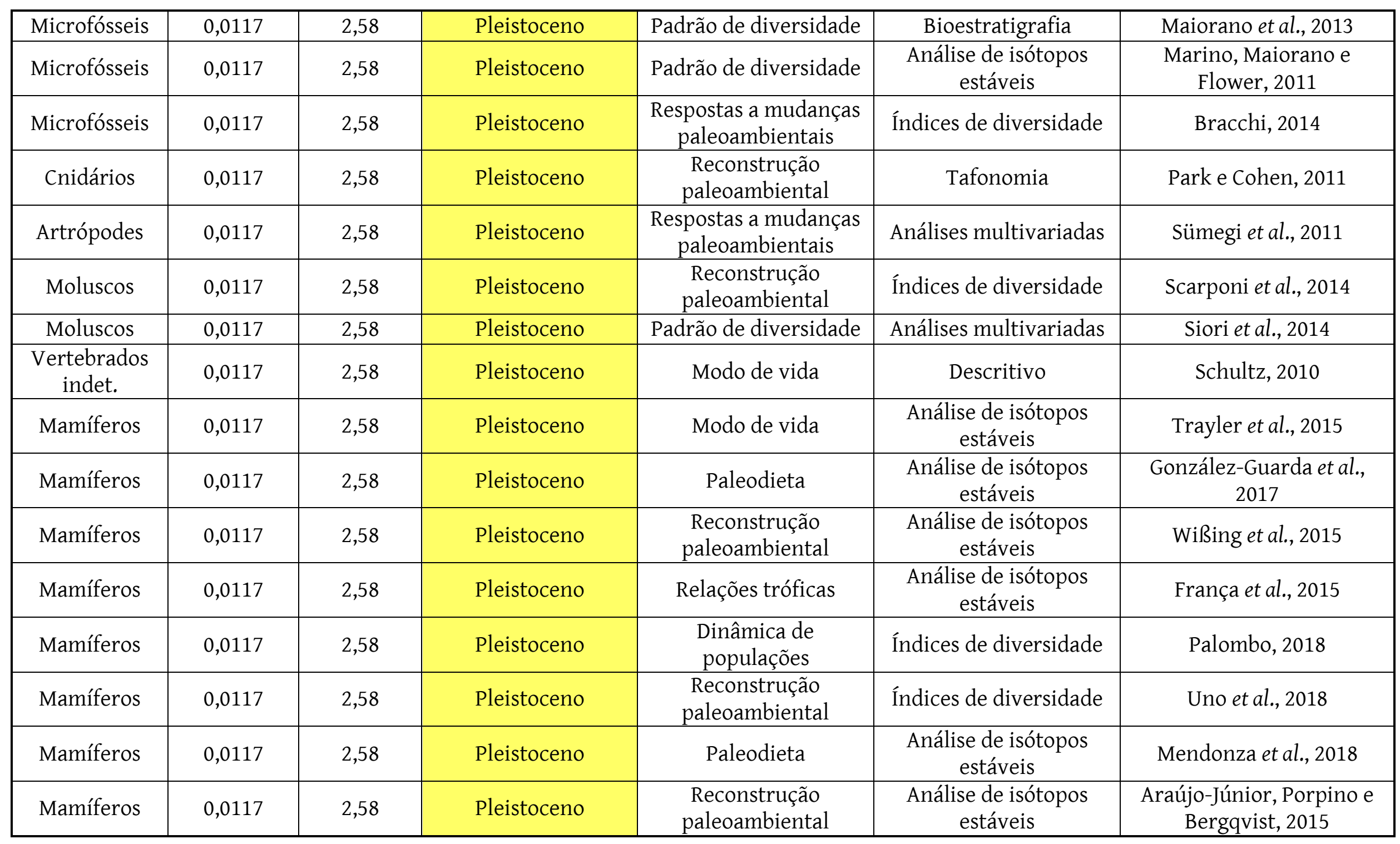




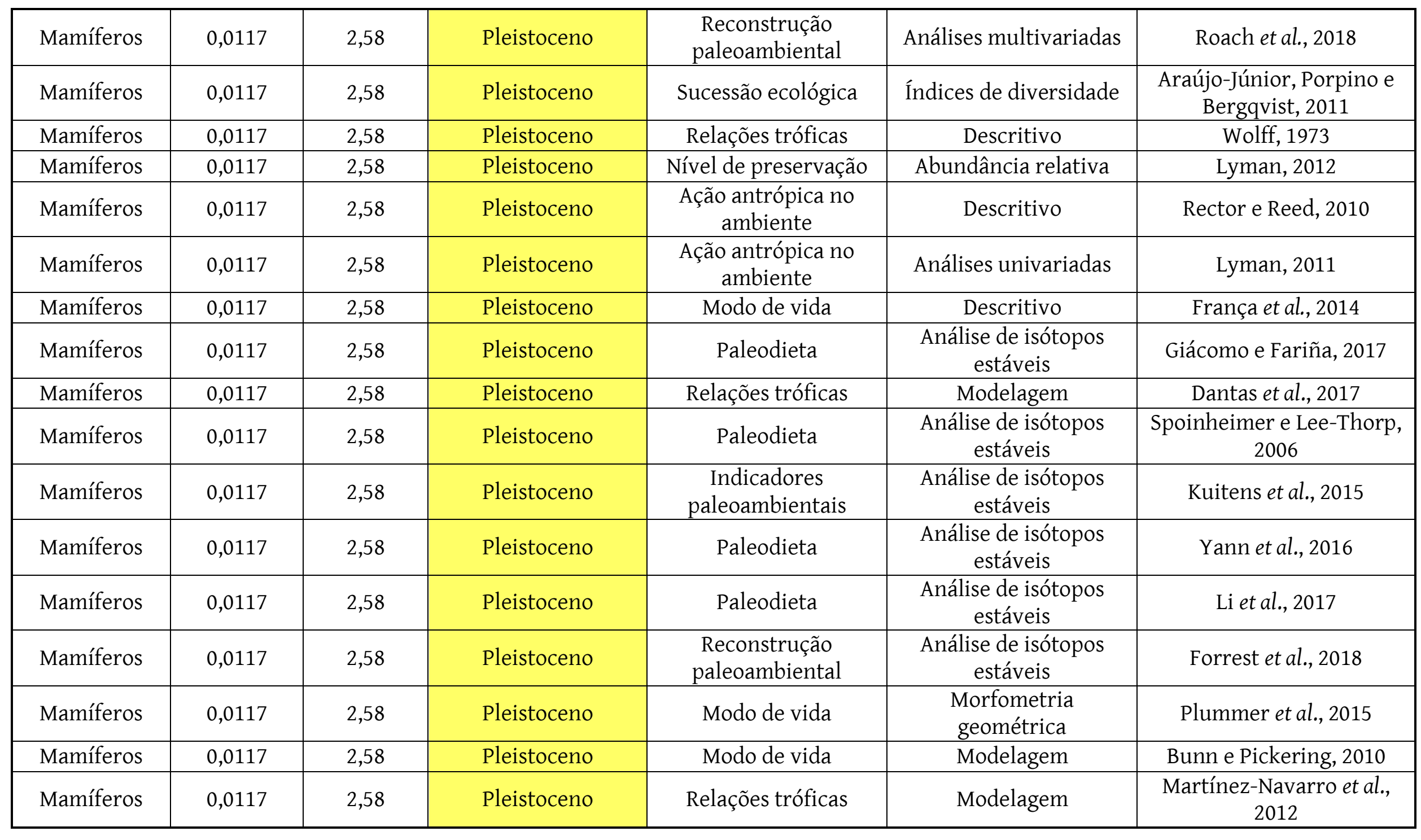




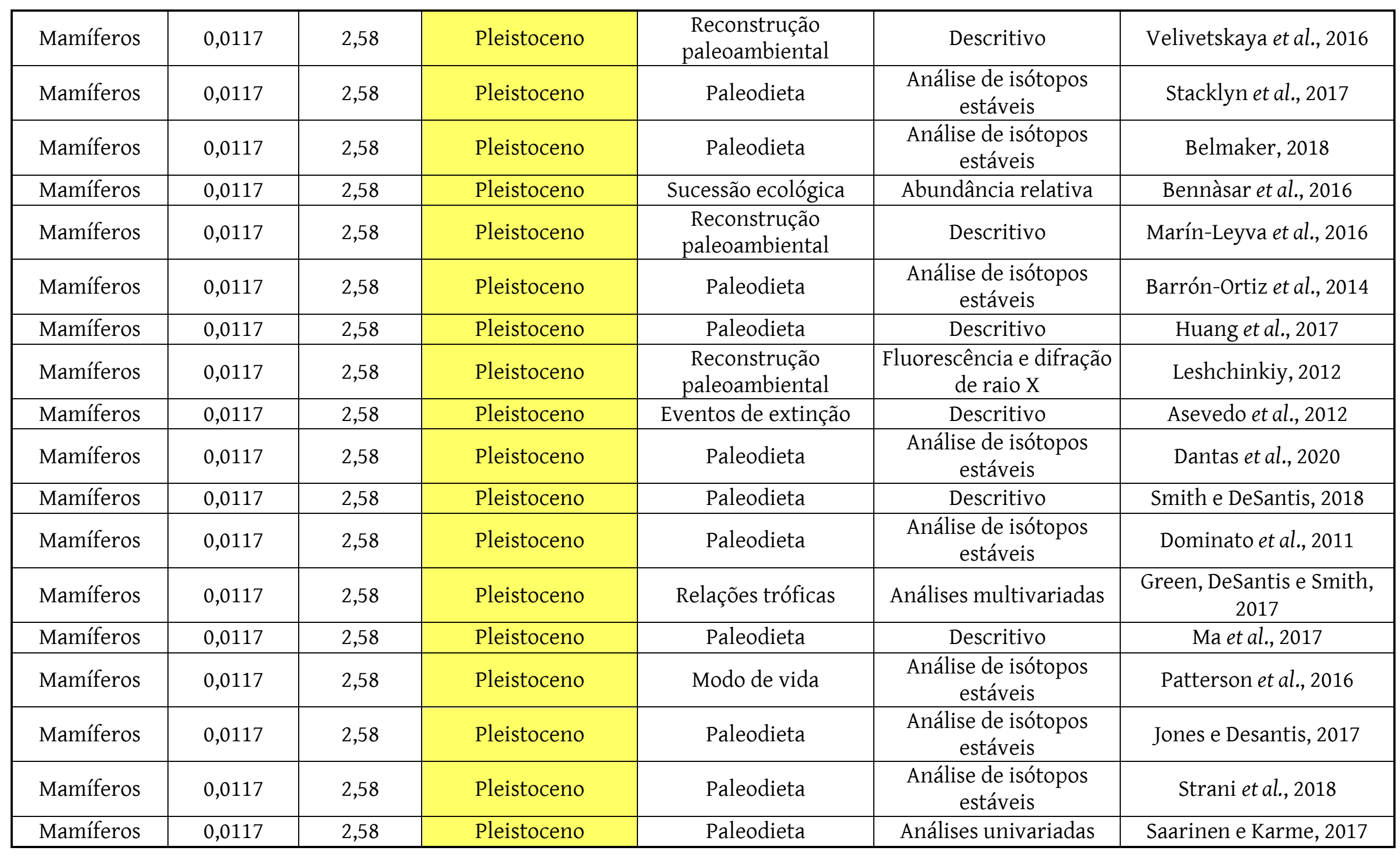




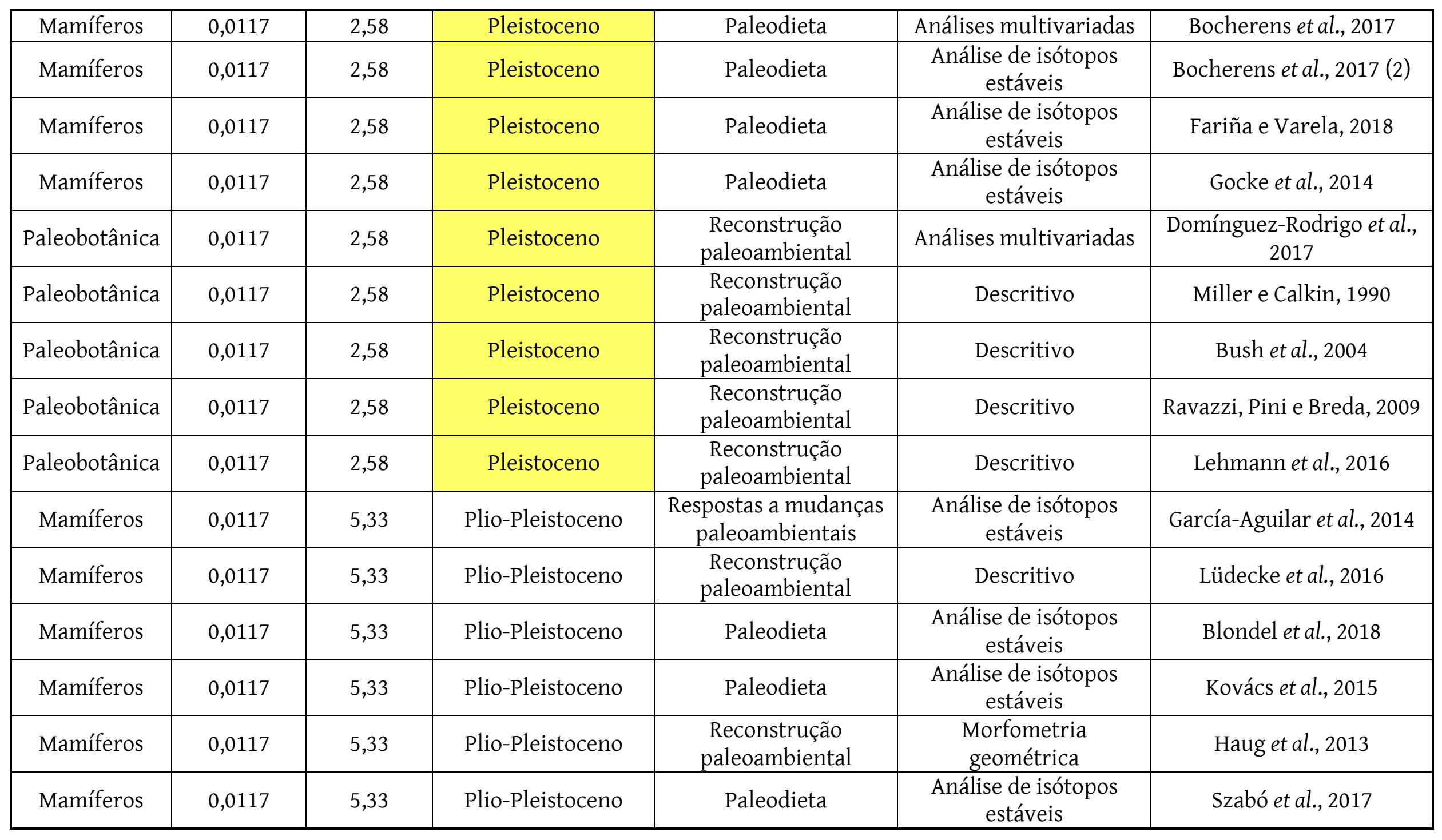




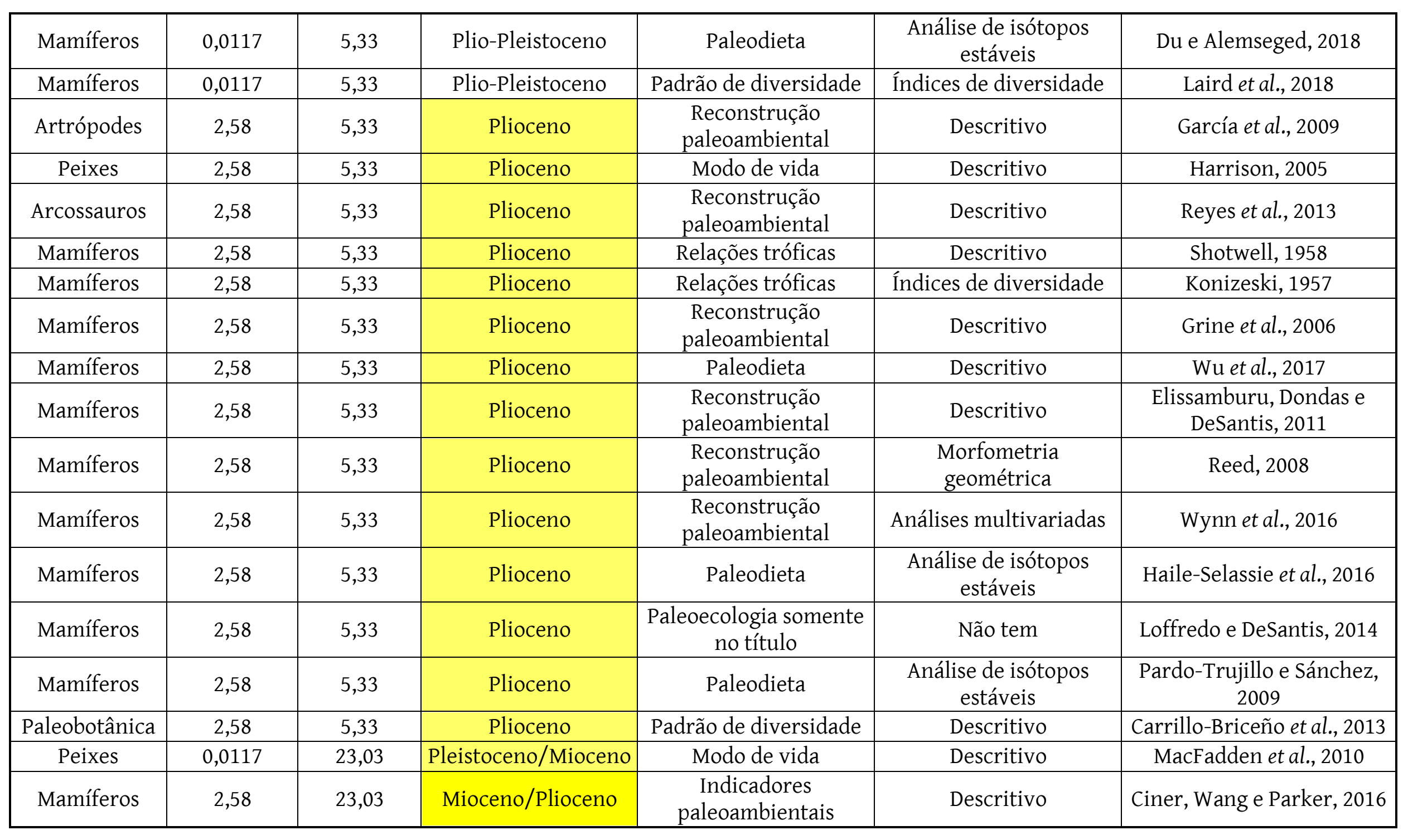




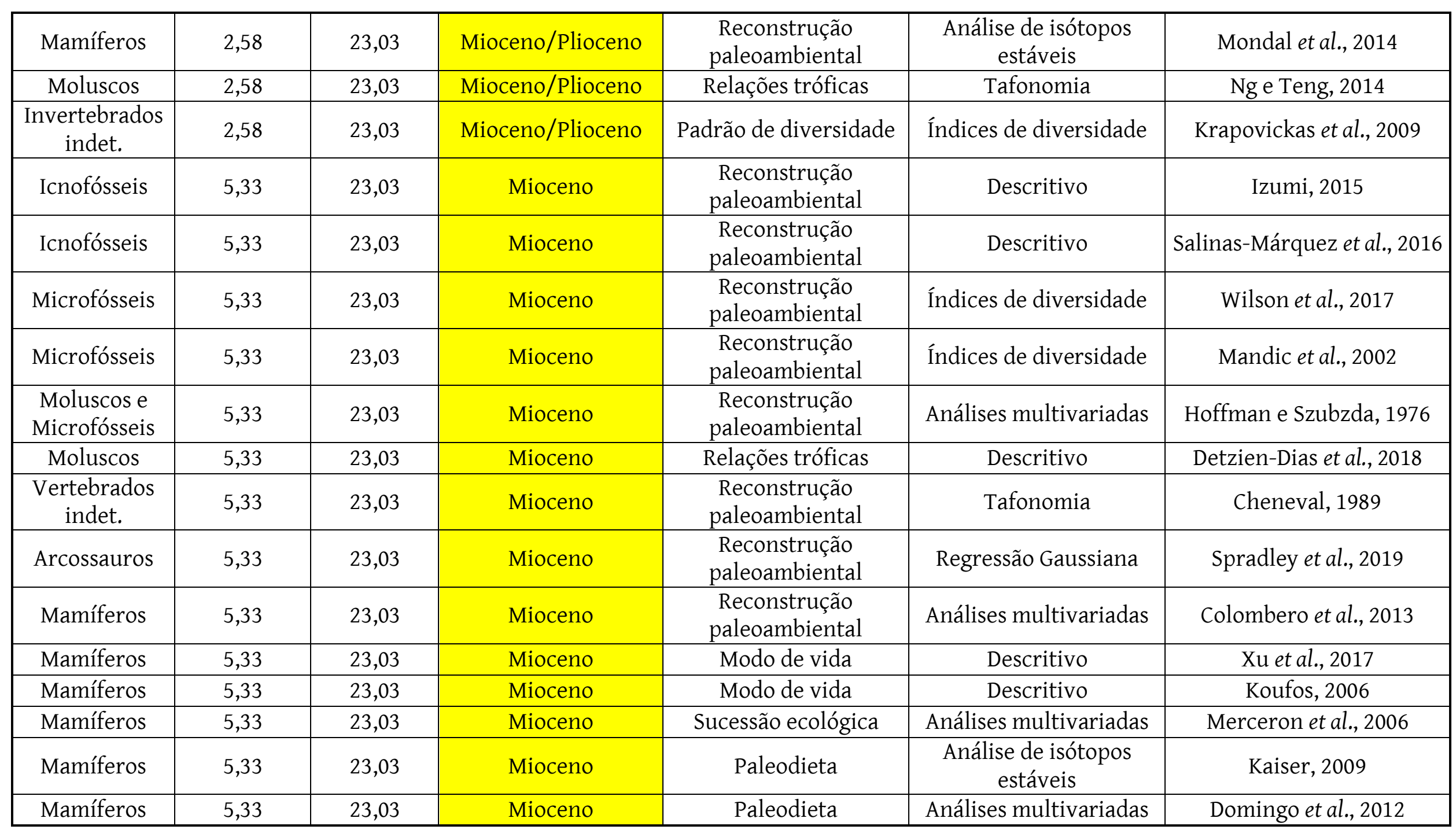




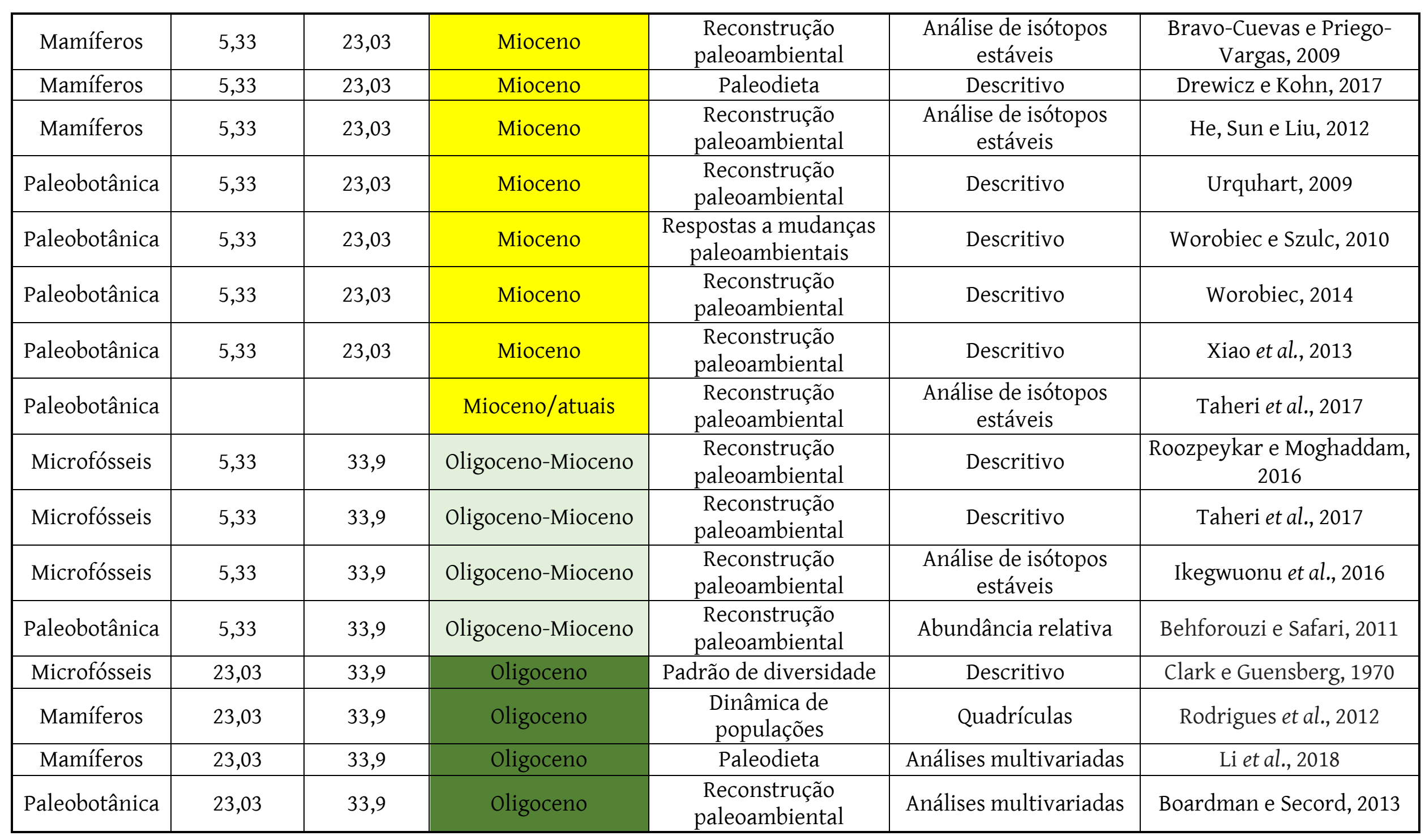




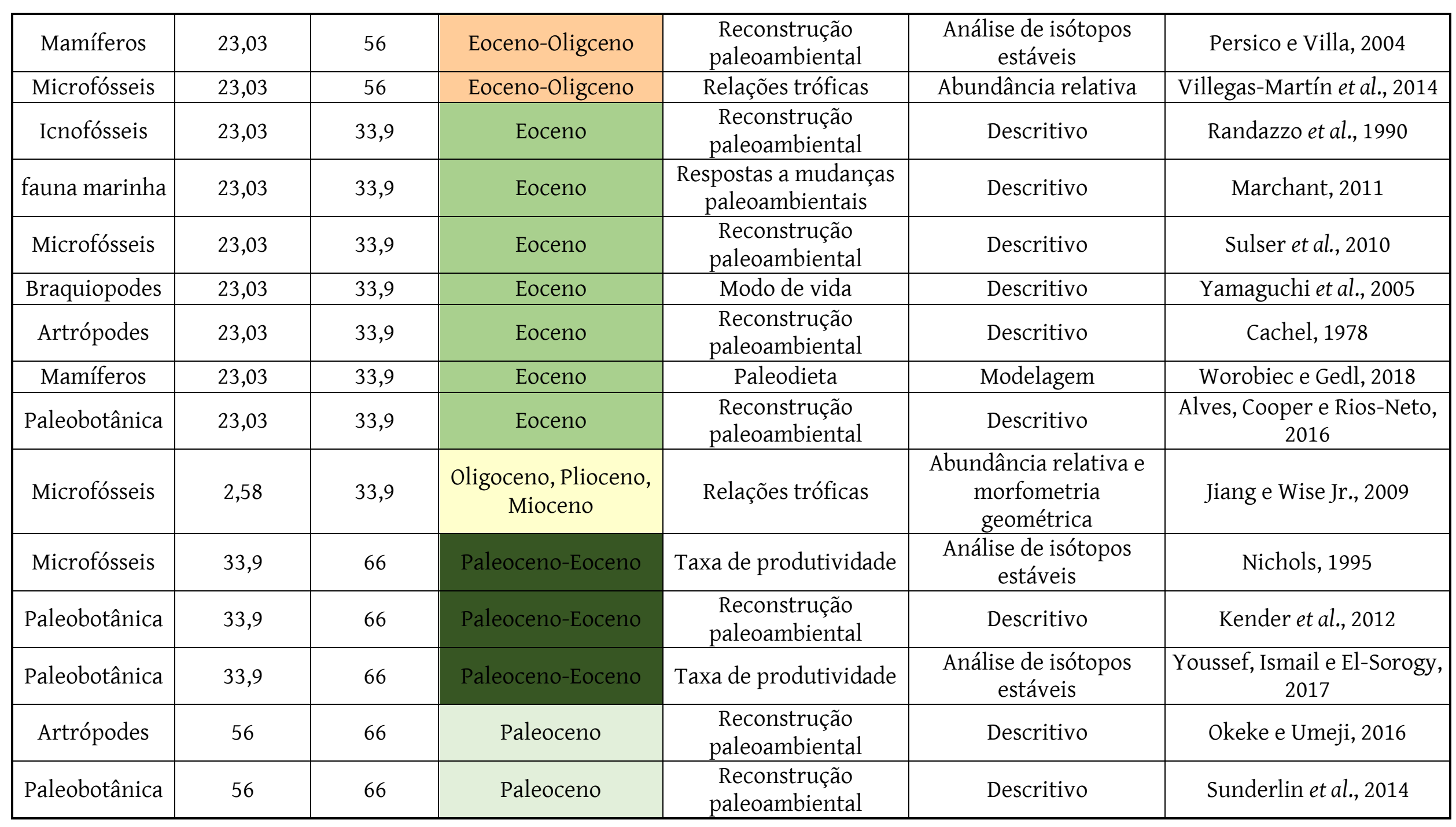




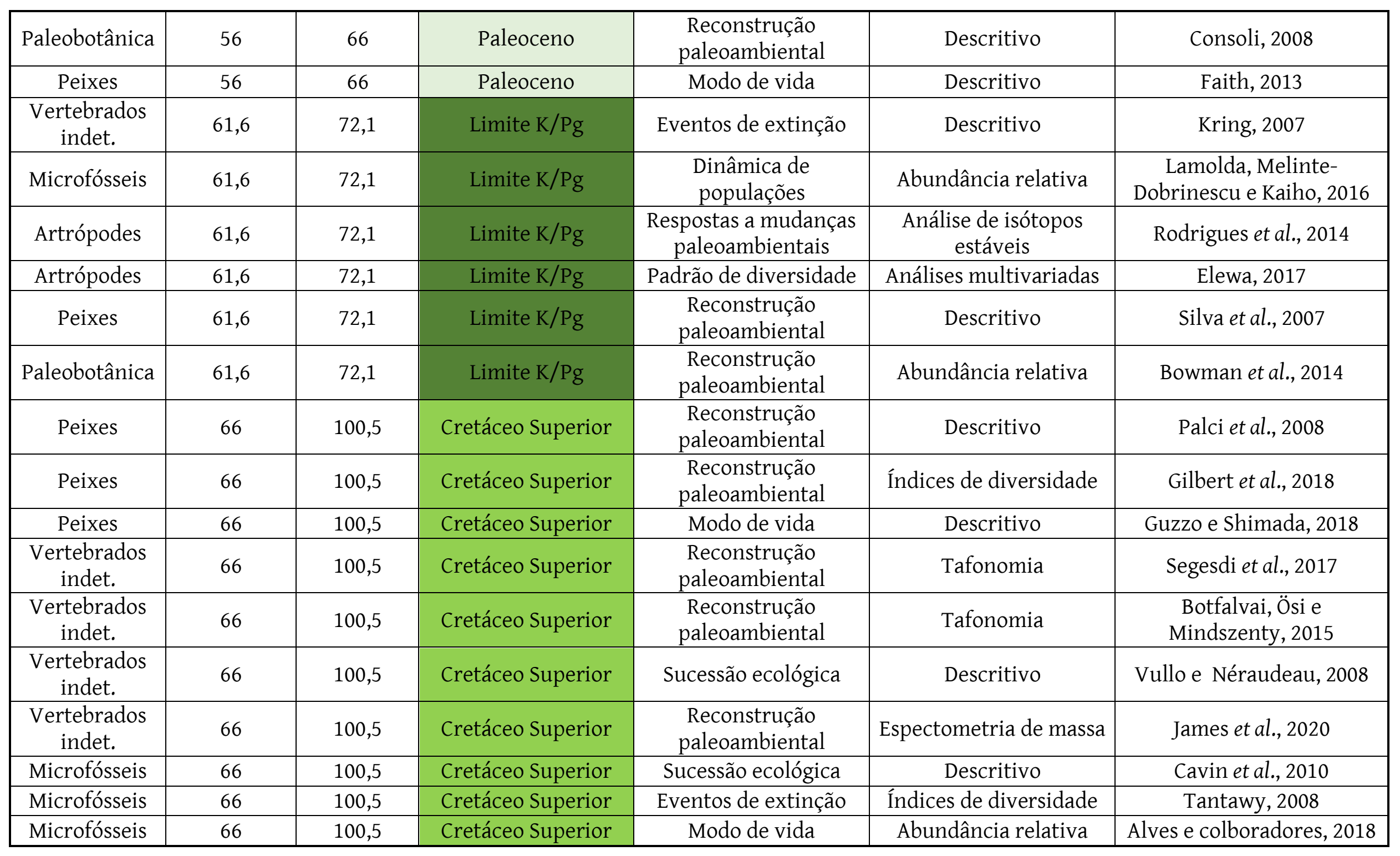




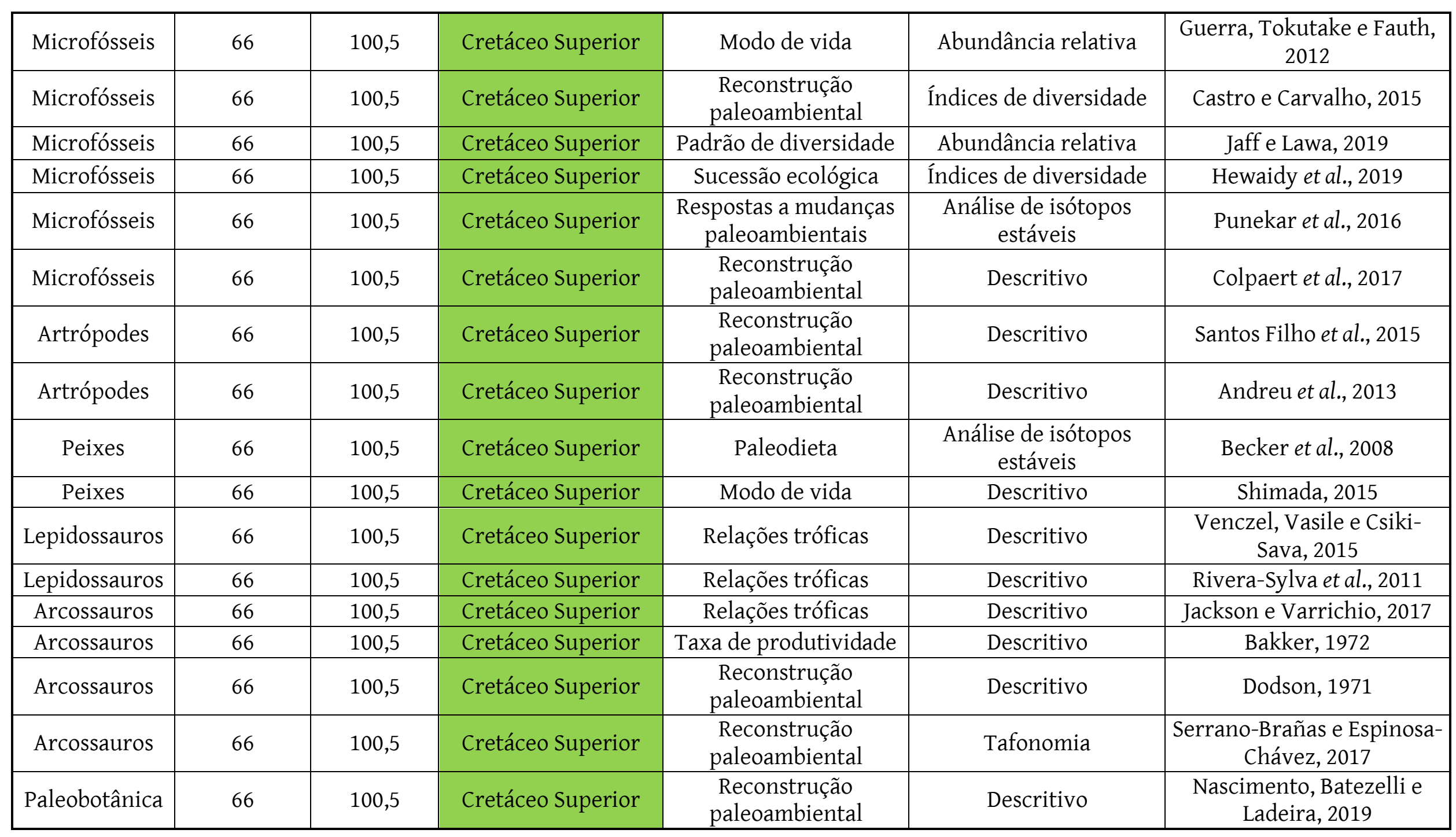




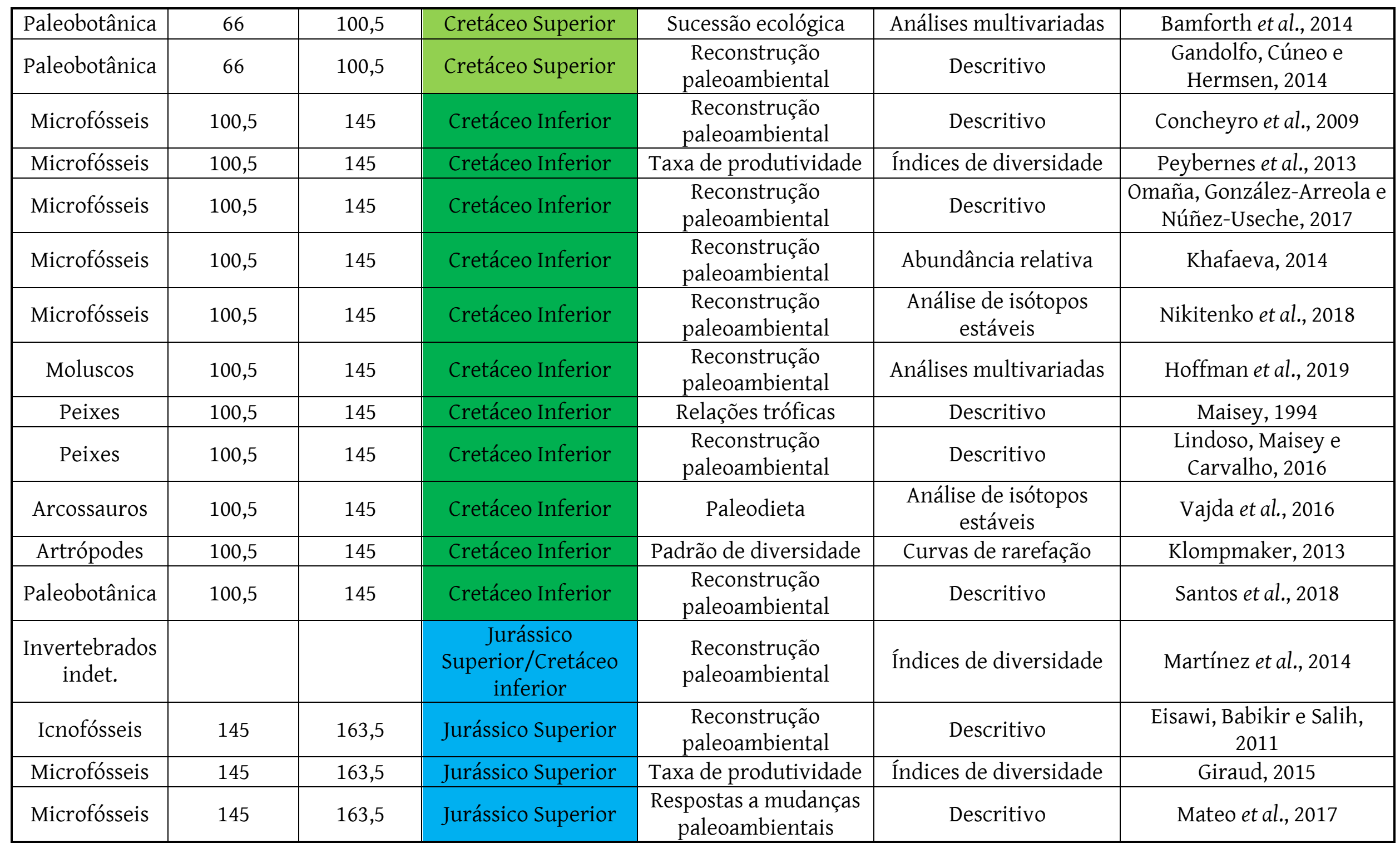




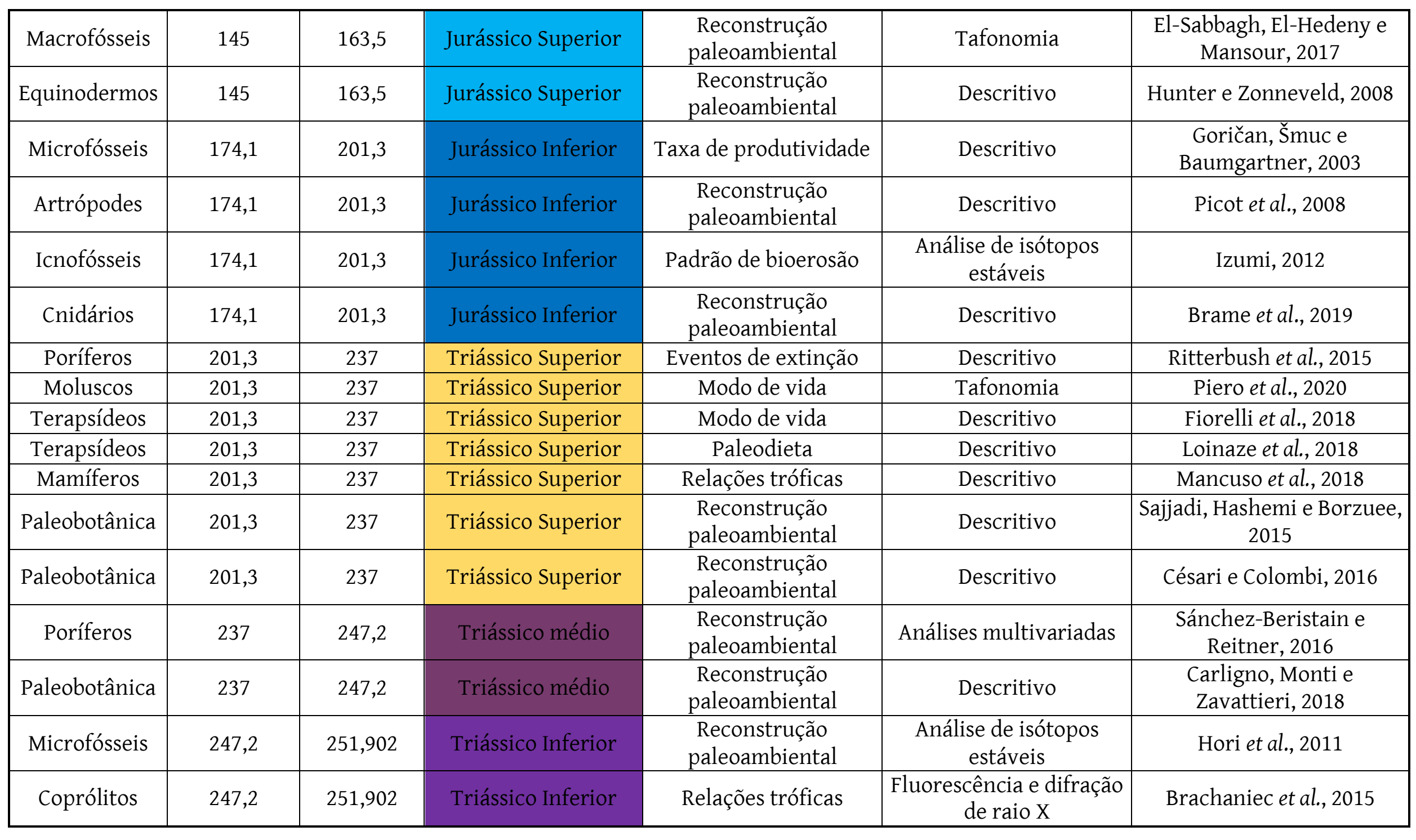




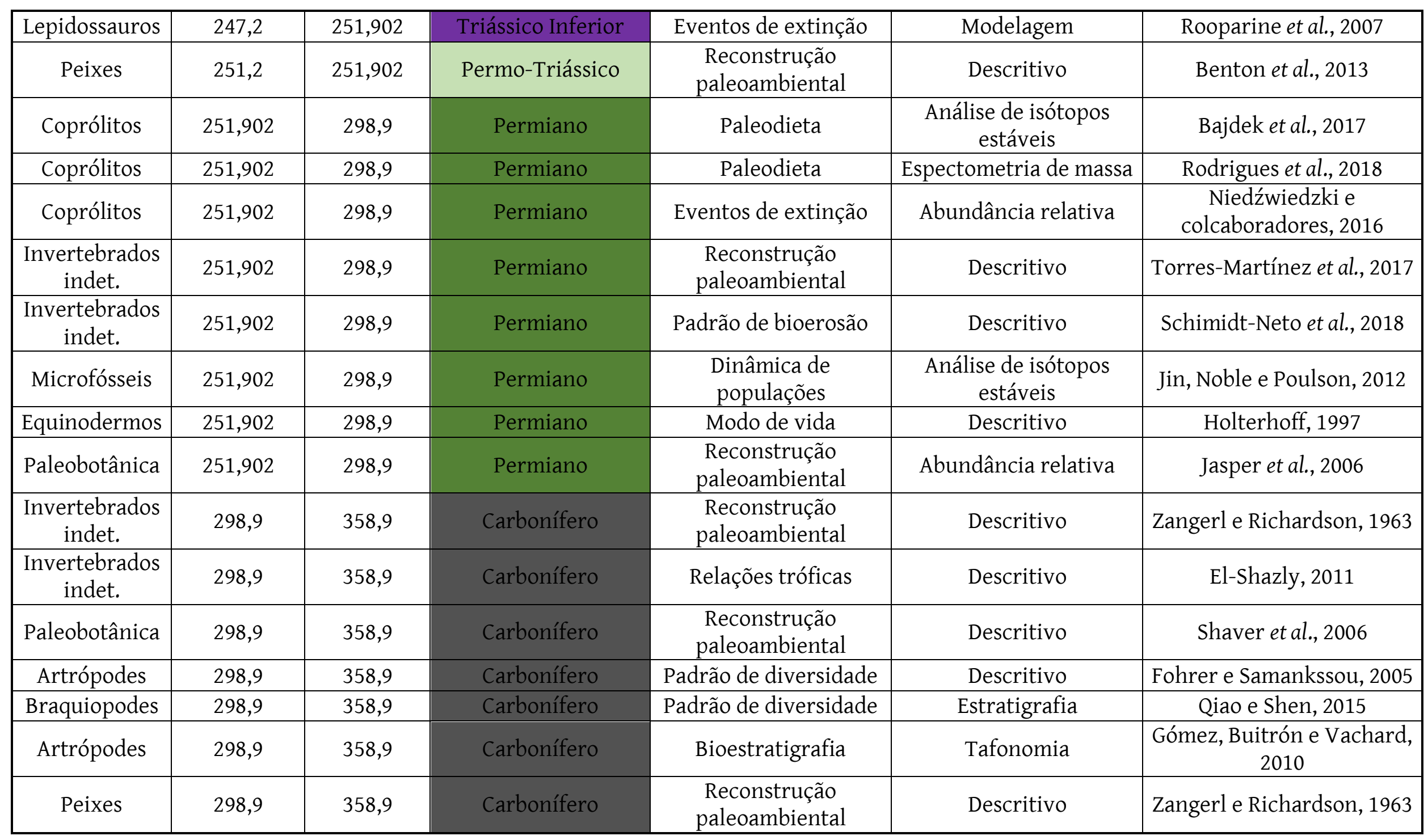




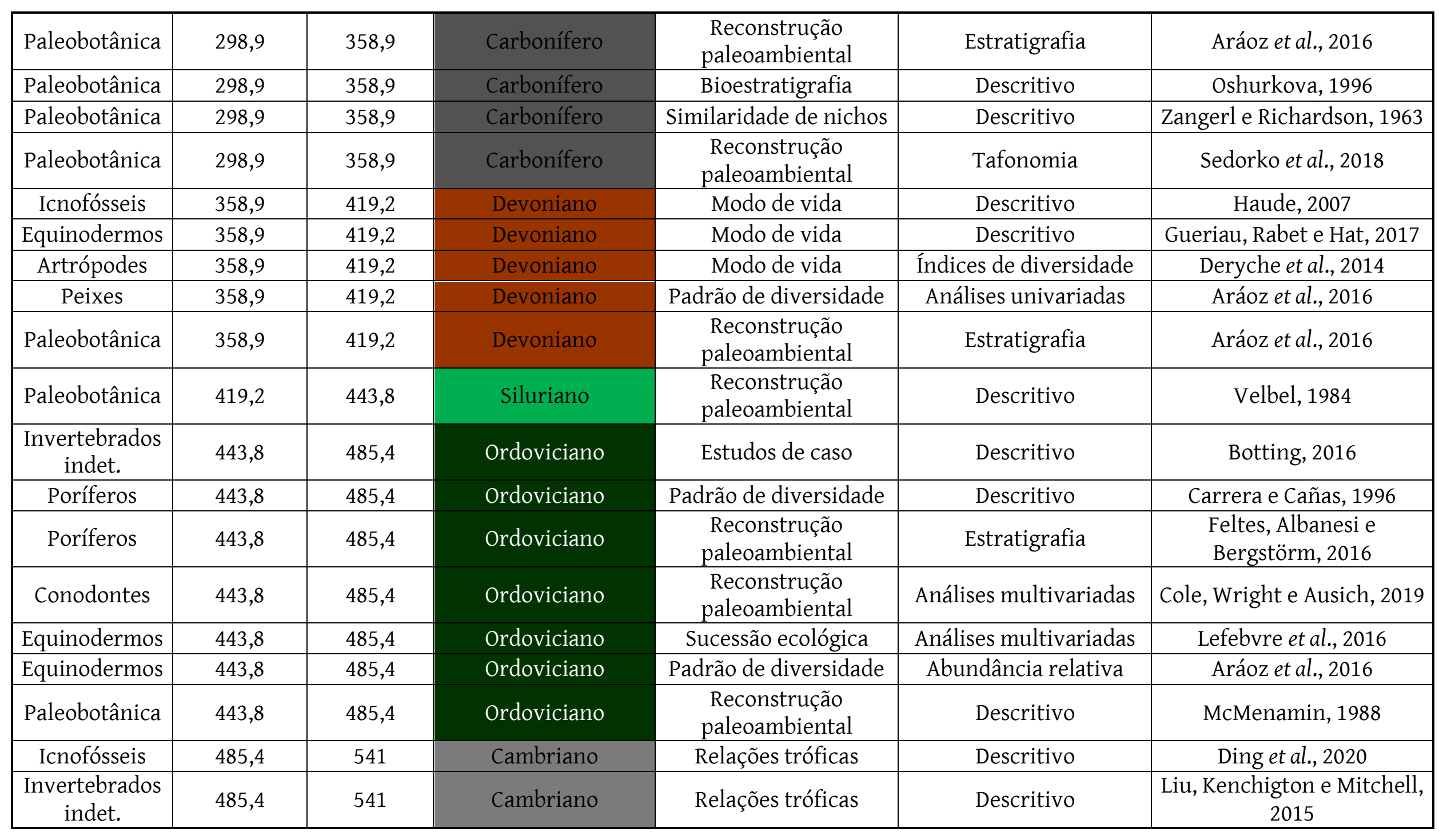




\begin{tabular}{|c|c|c|c|c|c|c|}
\hline Artrópodes & 635 & 1000 & Neoproterozoico & $\begin{array}{c}\text { Reconstrução } \\
\text { paleoambiental }\end{array}$ & Tafonomia & $\begin{array}{c}\text { Anticliffe, Hancy e Brasier, } \\
2015\end{array}$ \\
\hline Artrópodes & 635 & 1000 & Neoproterozoico & Relações tróficas & Índice de decaimento & Retallack, 2016 \\
\hline Artrópodes & 635 & 1000 & Neoproterozoico & $\begin{array}{c}\text { Reconstrução } \\
\text { paleoambiental }\end{array}$ & Estratigrafia & Reid et al., 2017 \\
\hline Artrópodes & 635 & 1000 & Neoproterozoico & Sucessão ecológica & Índices de diversidade & Zakrevskaya, 2014 \\
\hline Artrópodes & 635 & 1000 & Neoproterozoico & $\begin{array}{c}\text { Reconstrução } \\
\text { paleoambiental }\end{array}$ & Índices de diversidade & Beghin et al., 2017 \\
\hline
\end{tabular}

\section{(cc) $\mathrm{EY}$}

Este trabalho está licenciado com uma Licença Creative Commons - Atribuição 4.0 Internacional. 